Fernández Díaz, A., Bernal-Casasola, D., Castillo Alcántara, G. y Vargas Girón, J.M. (2019): "Los restos pictóricos del "Testaccio" haliéutico de Gades (El Olivillo, Cádiz).

Primera muestra del primer estilo pompeyano en la Bética". Spal 28.2: 203-234. DOI: http://dx.doi.org/10.12795/spal.2019.i28.20

\title{
LOS RESTOS PICTÓRICOS DEL "TESTACCIO" HALIÉUTICO DE GADES (EL OLIVILLO, CÁDIZ). PRIMERA MUESTRA DEL PRIMER ESTILO POMPEYANO EN LA BÉTICA
}

\section{PICTORIAL REMAINS OF THE HALIEUTIC “TESTACCIO" OF GADES (EL OLIVILLO, CÁDIZ). FIRST SAMPLE OF THE FIRST POMPEIAN STYLE IN THE BÉTICA}

\author{
ALICIA FERNÁNDEZ DÍAZ \\ Área de Arqueología del Departamento de Prehistoria, Arqueología, Ha. Antigua, Ha. Medieval y CC.TT. Historiográficas \\ de la Facultad de Letras de la Universidad de Murcia. C/ Santo Cristo, s/n, Campus de la Merced (30001) Murcia \\ Correo-e: aliciafd@um.es. (D) http://orcid.org/0000-0002-3083-6277 \\ DARÍO BERNAL-CASASOLA \\ Área de Arqueología del Departamento de Historia, Geografía y Filosofía de la Facultad de Filosofía y Letras \\ de la Universidad de Cádiz. Avda. Dr. Gómez Ulla s/n 11003, Cádiz \\ Correo-e: dario.bernal@uca.es. (D) https://orcid.org/0000-0003-1107-5318 \\ GONZALO CASTILLO ALCÁNTARA \\ Área de Arqueología del Departamento de Prehistoria, Arqueología, Ha. Antigua, Ha. Medieval y CC.TT. Historiográficas \\ de la Facultad de Letras de la Universidad de MurciaC/ Santo Cristo, s/n, Campus de la Merced (30001) Murcia \\ Correo-e: gonzalo.castillo@um.es. D http://orcid.org/0000-0003-3908-219X \\ JOSÉ MANUEL VARGAS GIRÓN \\ Área de Arqueología del Departamento de Historia, Geografía y Filosofía de la Facultad de Filosofía y Letras \\ de la Universidad de Cádiz. Avda. Dr. Gómez Ulla s/n 11003, Cádiz \\ Correo-e: josemanuel.vargas@uca.es. D https://orcid.org/0000-0003-2882-8902
}

\begin{abstract}
Resumen: Este trabajo aborda el análisis de un conjunto de restos pictóricos procedentes de un vertedero de ingentes dimensiones excavado en el solar de El Olivillo en la ciudad de Cádiz, en 2016, interpretado como un Testaccio haliéutico portuario, y fechado entre los ss. I a.C. y I d.C. De entre los restos obliterados en el mismo, destacamos los que suponen la primera muestra conocida del primer estilo pompeyano en toda la Bética, lo que conlleva un avance en el conocimiento de la difusión de la pintura mural romana en Hispania y, por ende, un conocimiento mayor de la edilicia republicana en la ciudad. Desde una perspectiva integral, se abordan los aspectos técnicos y estilísticos mediante el uso de diversos análisis físico-químicos.

Palabras clave: Primer estilo pompeyano, Cádiz, Bética, análisis, mortero.
\end{abstract}

\begin{abstract}
In this paper we analyze a group of Roman wall paintings from the excavation of the dump called El Olivillo in Cádiz, in 2016. This archaeological site has been identified as a huge dump at the harbor area, which has been defined as the Halieutic Testaccio and dated between $1^{\text {st }}$ century BC and $1^{\text {st }}$ century AD. These fragments are a first-time evidence of the First Pompeian Style in the Bética, being a remarkable step-forward on the knowledge of the diffusion of the Roman Wall painting in Hispania as well as the republican period in Cádiz. From a comprehensive perspective, here we analyze technical and stylistic aspects using different physical and chemial analysis.
\end{abstract}

Keywords: First Pompeian style, Cádiz, Bética, analysis, mortar. 


\section{INTRODUCCIÓN}

El Vicerrectorado de Infraestructuras y Patrimonio de la Universidad de Cádiz comenzó durante el segundo semestre del año 2016 un proceso de rehabilitación, remodelación y acondicionamiento del edificio de El Olivillo para su reconversión en Centro de Transferencia Empresarial, motivo por el cual se realizó una Actividad Arqueológica Puntual en la zona de la parcela que se encuentra al aire libre, correspondiente con la trasera del citado inmueble. Constituía esta una oportunidad notable para recabar datos estratigráficos y funcionales sobre la topografía y el urbanismo de la antigua ciudad de Gades, muy mal conocida aún en su problemática histórico-arqueológica (Bernal y Lara 2012), por lo que debido a su potencialidad científica esta actuación ha sido dirigida por el Área de Arqueología de la institución universitaria gaditana.

Los trabajos arqueológicos llevados a cabo en este emblemático edificio del Centro Histórico de la ciudad han consistido en la realización de 9 sondeos estratigráficos repartidos por toda la superficie del solar $\left(450 \mathrm{~m}^{2}\right)$ y una fase de documentación durante la ejecución del control de los movimientos de tierra.

Se ha podido documentar una secuencia estratigráfica muy amplia, que abarca desde la Prehistoria Reciente hasta época moderna-contemporánea, pero sin lugar a dudas, el momento de mayor actividad en la zona se centra en época romana. De esta fase destacamos principalmente el hallazgo de un vertedero urbano de ingentes dimensiones, del cual se ha podido excavar una potencia máxima de 5 metros de altura y más de 10 metros de longitud, si bien hemos podido detectar que sus dimensiones serían, en origen, mucho mayores, ya que ha sido alterado tanto en la parte alta de la secuencia como en sus laterales por estructuras de época moderno-contemporánea. Este depósito, al estar conformado en su práctica integridad por residuos de la industria pesquero-conservera (ánforas, restos de la limpieza y despiece de pescado, concheros para la producción de púrpura marina...), ha sido interpretado como un Testaccio haliéutico, actualmente en fase de estudio y caracterización, y del cual se han presentado los primeros avances, en buena parte aún en prensa, centrados en la problemática interpretativa del depósito (Bernal et al. 2017a) y en la presentación de algunos materiales singulares (Bernal y Vargas 2017; Bernal et al. 2017b), como podría ser este el caso.

De la fase romana de El Olivillo hemos podido distinguir dos subfases bien diferenciadas, aunque la funcionalidad del espacio -vertedero urbano de residuos sólidos- no varía de un momento a otro, si bien en el momento más antiguo los orígenes del vertedero se relacionan con restos de desescombro de edificaciones, siendo a partir de época augustea cuando la vocación de este tell artificial es el desechado prácticamente exclusivo de residuos de las industrias pesquero-conserveras urbanas, situadas en las inmediaciones. La fase más antigua se fecha en el siglo I a.C., situándose algunos de los vertidos en el segundo cuarto de esta centuria (75-50/40 a.C.), gracias a numerosas evidencias de cultura material, destacando especialmente la presencia de ánforas (ovoides, Dr. 1 itálicas y de producción regional, ánforas tardopúnicas), junto a vajilla (barniz negro, barniz rojo púnico-gaditano, lucernas, paredes finas); y la total ausencia de otras producciones como la terra sigillata itálica o las lucernas de volutas (Bernal y Vargas 2017: 36). La fase posterior, sin solución de continuidad, se sitúa entre época augustea y momentos claudio-neronianos o poco posteriores (Bernal et al. 2017a), encontrándose alterada la parte superior de la secuencia, lo que impide verificar la continuidad del depósito con posterioridad. El hecho de no haber encontrado ningún fragmento de sigillata clara, ni siquiera en aquellos niveles que han sufrido alteraciones en épocas posteriores, es un claro indicio para plantear el cese de la actividad en el vertedero de El Olivillo durante el siglo I d.C. (Bernal y Vargas 2019).

Por lo general, los niveles que conforman esta montaña artificial se caracterizan por presentar una composición muy heterogénea, así como por un marcado buzamiento en dirección oeste-este, lo cual nos ha permitido dibujar ciertos rasgos de la paleotopografía del terreno. Se ha excavado parcialmente la ladera oriental en la cual se habrían vertido estos depósitos, formados, en un alto porcentaje, por restos de ánforas. Por lo tanto, la razón de ser de este yacimiento debe entenderse como un montículo en el cual se vertieron las descargas de las cercanas fábricas de salazón excavadas en el entorno (cetariae de La Caleta, del Cine Cómico y del antiguo Teatro Andalucía), de ahí su relación con la industria pesquero-conservera, algo que ha quedado claramente verificado por la ingente cantidad de restos de ictiofauna documentados en el proceso de excavación. Si bien es cierto que los niveles documentados en El Olivillo son fundamentalmente de carácter industrial, determinados restos de cultura material han evidenciado otro tipo de descargas. Se trata de vertidos de carácter doméstico -amén de la abundante presencia de cerámica común a torno y de vajilla fina de mesa-, vertidos generados por el depósito 
de grandes cantidades de escombros relacionados con destrucciones y/o reparaciones de edificios, presumiblemente cercanos, donde han aparecido numerosos restos de materiales constructivos, así como interesantes evidencias de pintura mural y estuco, especialmente en las capas más antiguas del depósito, que serán los que analicemos en este trabajo.

Como puede observarse, los vertederos constituyen un ejemplo particular de yacimiento que, además de resultar un contexto idóneo para obtener cronologías cerradas, aportan información acerca de las dinámicas urbanas y económicas de una ciudad a través del estudio de los materiales arqueológicos que se vierten en ellos, ya sean materiales cerámicos, elementos constructivos $\mathrm{u}$ objetos de uso personal, entre otros. Por ello, aunque en muchas ocasiones se dejen al margen los aspectos relativos a la gestión de los residuos en época antigua, algo que no es circunstancial como hemos podido ver por la cantidad de vertederos hallados en otros contextos urbanos (Remolà y Acero 2011; Acero 2015), y a pesar de la dificultad que presentan a la hora de determinar la procedencia de estos dentro de una ciudad, cada vez sean más importantes los estudios sobre los elementos decorativos que aparezcan en este tipo de yacimientos.

El caso que nos ocupa reviste gran importancia por dos cuestiones: en primer lugar, por incluir en su contenido el primer ejemplo del primer estilo pompeyano hallado en la Bética, y en concreto en Cádiz, que ayuda a asentar con datos la convicción o certidumbre que se tenía hasta ahora sobre la existencia de este tipo de decoración pictórica en dicha ciudad, dado su largo desarrollo histórico desde época fenicia; y en segundo lugar, por su hallazgo dentro del propio vertedero, que si bien nos impide conocer su procedencia exacta, nos permite extraer otros interesantes datos como son el uso continuado de un espacio como vertedero a lo largo de varios siglos, tal y como demuestra el material recuperado, pero sobre todo, la existencia clara de una fase edilicia tardorrepublicana en la ciudad. Con respecto a esto último, su comparación con los datos obtenidos en otros vertederos urbanos peninsulares, como el del suburbio Norte de Augusta Emerita que contempla seis siglos de rellenos con restos pictóricos del tercer y cuarto estilo pompeyano (Heras et al. 2014), así como una completa ausencia de elementos de época tardorrepublicana que coinciden con la fecha de fundación de la ciudad, completa el panorama más desconocido de las fases más antiguas de cada una de las ciudades romanas peninsulares que cuentan con este tipo de restos.

\section{LOCALIZACIÓN DEL YACIMIENTO Y CONTEXTO HISTÓRICO-ARQUEOLÓGICO}

Los trabajos arqueológicos realizados en el edificio de El Olivillo han permitido descubrir un yacimiento que se encontraría situado en la isla pequeña del antiguo archipiélago de Cádiz, islote que tradicionalmente ha venido conociéndose como Erytheia. Es un yacimiento, además, que se encuentra muy próximo al mar, situándose al borde del antiguo Canal Bahía-Caleta, brazo de mar que en la Antigüedad dividía a Gadir/Gades en dos islas. En términos actuales, el Edificio de El Olivillo se encuentra situado en el Centro Histórico de la capital gaditana, concretamente en la Glorieta de Simón Bolívar, al final de la Avda. Dr. Gómez Ulla y como parte del frente universitario del Campus de Cádiz, muy cerca de la playa de la Caleta (fig. 1).

El Olivillo se enmarca, desde un punto de vista espacial, en una zona de gran importancia histórico-arqueológica, ya que en el perímetro más próximo a nuestro solar se ha podido documentar un registro que ha determinado una intensa ocupación desde época prehistórica hasta la actualidad, con un hiatus de tiempo correspondiente a la Edad Media y los primeros siglos de la modernidad, momentos en que este sector podría haber sido destinado a campos de cultivos.

Pero el Testaccio haliéutico de El Olivillo no ha sido el único yacimiento de la zona donde han aparecido evidencias de pinturas murales romanas. En este sentido, se conocen al menos 6 intervenciones arqueológicas donde han aparecido este tipo de restos. De todos los yacimientos documentados en el entorno, no cabe la menor duda que el más cercano de todos corresponde al excavado en la calle Dr. Gregorio Marañón, situado a escasos metros de El Olivillo (fig. 1.1). En total han sido tres las campañas arqueológicas realizadas, correspondientes a otros tantos solares contiguos (Expósito 2007: 113): la primera de ellas en 1985 (Perdigones y Muñoz 1987), la segunda en 1987 (Perdigones y Muñoz 1990) y finalmente una última campaña durante 1989 (Blanco 1991). En todos los casos los resultados arqueológicos fueron positivos, sobre todo en el último año de excavación, donde se descubrieron una serie de restos estructurales vinculados a instalaciones industriales, así como un vertedero generado durante el siglo I a.C.: en dos de los siete niveles que conforman esta gran escombrera (niveles 2 y 4 ) aparecieron fragmentos de estuco asociados a descargas de material cerámico, principalmente ánforas (Expósito 2007: 117).

Otro yacimiento descubierto en el entorno de El Olivillo, y quizás el más importante en cuanto a 


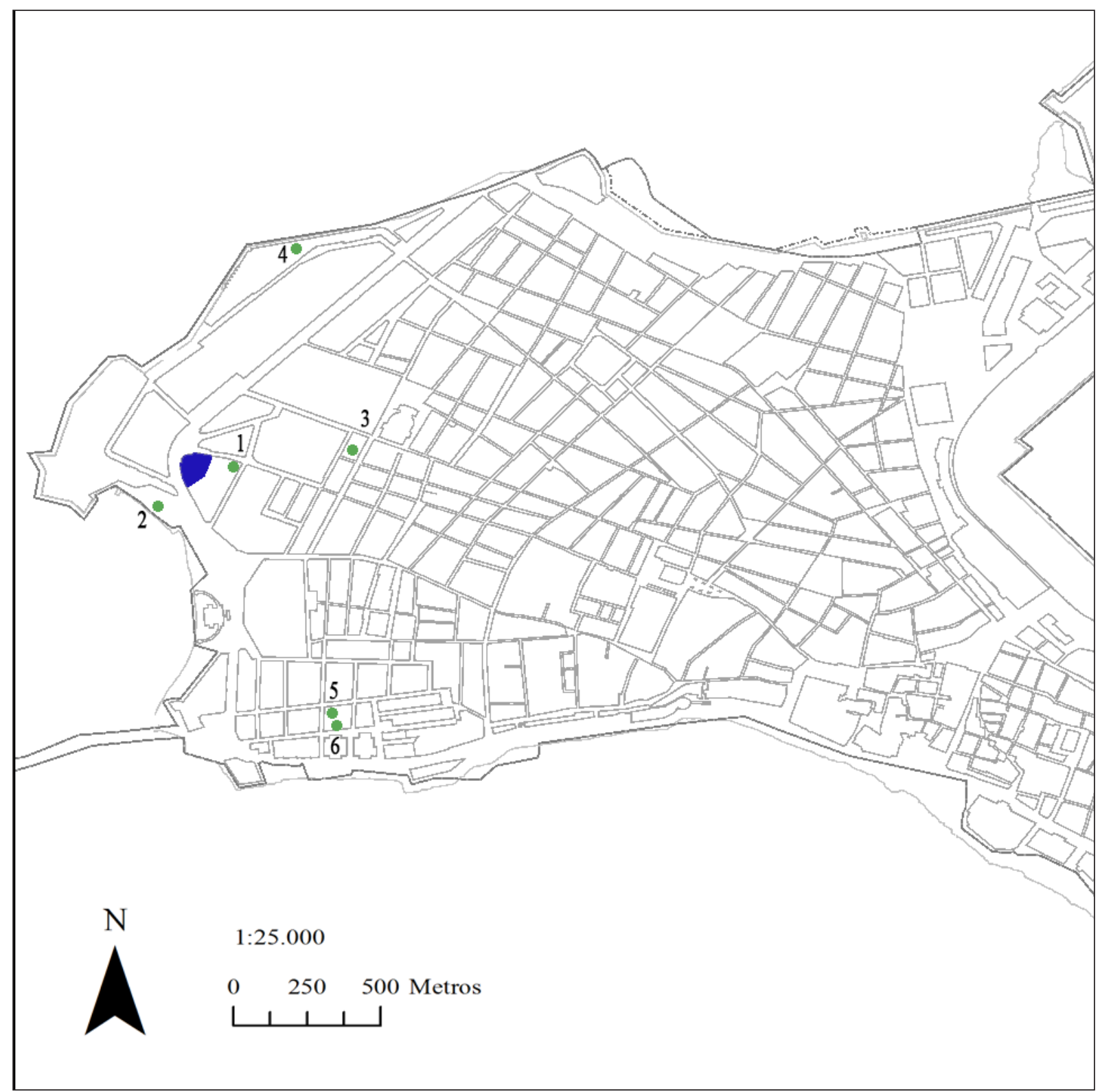

Figura 1. Localización geográfica del Edificio El Olivillo de Cádiz. En color azul señalamos el solar donde hemos intervenido y los puntos verdes indican las intervenciones del entorno donde han aparecido restos de estuco y pintura mural. 1: c/ Gregorio Marañón 22. 2: Club Náutico La Caleta. 3: c/ Chile 2-4 - c/ San Rafael 5. 4: Aparcamiento subterráneo de Santa Bárbara. 5: c/ Pericón de Cádiz 10. 6: c/ Venezuela 3.

pintura mural se refiere, es el conocido como Club Náutico La Caleta (fig. 1.2). Con motivo de la construcción del nuevo edificio recreativo enclavado en la playa de la Caleta, en pleno casco histórico de la ciudad de Cádiz y a escasos metros del solar objeto de estudio, se llevaron a cabo tres sondeos arqueológicos y una excavación en extensión en la zona de afección por la obra, habiéndose documentado restos arqueológicos de época romana y moderna. Las evidencias de mayor entidad las componen una serie de estructuras pertenecientes a una factoría de salazón romana que ha sido datada en torno al siglo I a.C. - I d.C., y de la que apenas se conocen datos relativos al contexto material recogido durante los trabajos de excavación, si 
bien sabemos que en los niveles existentes sobre el área pavimentada aparecieron abundantes restos de pintura mural, algunos incluso ricamente decorados para pertenecer a un contexto funcional como este (Expósito 2007: 131; Fernández Díaz 2010: 210 y 213), parte de los cuales están expuestos en el Museo de Cádiz.

Otra de las intervenciones realizadas cerca de El Olivillo corresponde al solar de la calle Chile 2-4 esquina a calle San Rafael 5 (fig. 1.3). Como consecuencia de la construcción de edificios de nueva planta, se llevó a cabo, en dos fases, un diagnóstico del solar que nos ocupa. Durante la primera fase, realizada en el año 2000, se realizó un sondeo de 2 x 2 metros en la zona central de la parcela, documentándose una escombrera de ánforas y restos de materiales constructivos de época romana. En uno de los niveles que conforman este vertedero, aparecieron restos de estuco asociados a fragmentos de opus signinum, semillas quemadas y evidencias de argamasa blanquecina (Pajuelo 2000). Los resultados más importantes se obtuvieron, sin embargo, durante la segunda fase de intervención, habiéndose podido documentar un vertedero de época romana imperial entre cuyos materiales han aparecido restos de pintura mural asociados a otros elementos constructivos tales como ladrillos y fragmentos de pavimentos, todo ello mezclado con descargas de contenedores anfóricos, cerámica común, vajilla fina de mesa y vidrio (Pajuelo 2001).

Un yacimiento cercano donde han aparecido evidencias de estuco y pintura mural corresponde al aparcamiento subterráneo de Santa Bárbara (fig. 1.4), cuya secuencia estratigráfica ha permitido documentar niveles de ocupación prerromana y romana donde se han recuperado niveles de escombros con materiales procedentes de un ámbito doméstico, habiéndose localizado también restos pictóricos con decoración figurada (Pineda 2012).

Al otro lado del Canal Bahía-Caleta, contamos con interesantes yacimientos relacionados funcionalmente con El Olivillo. El primero de ellos corresponde a un solar excavado en la calle Pericón de Cádiz 10 (fig. 1.5) donde se han detectado dos fases de ocupación de época romana (siglos II a.C. - IV d.C.) en las cuales la zona sirvió de vertedero. En su fase más antigua este basurero ha deparado niveles de relleno o desechos conformados por materiales cerámicos (ánforas, cerámica común y terra sigillata), así como por fragmentos de materiales de construcción, entre los que aparecieron restos de pintura mural, tégulas, mortero y opus signinum (Blanes 1997). Muy cerca de este solar se realizó una intervención arqueológica en la calle Venezuela 3 (fig. 1.6) donde también aparecieron niveles de relleno de época romana con materiales constructivos y, entre ellos, restos pictóricos en tonos rojos, blancos y amarillos (Blanco 1996). Asimismo, aunque algo más alejado de la zona de estudio, se localizan los hallazgos pictóricos de la calle Santa María 17-19 (DomínguezBella et al. 2003), recuperados tras una intervención de urgencia en 2001, y los únicos que han sido analizados también a través de técnicas de laboratorio.

Este sucinto recorrido por las actuaciones arqueológicas cercanas que han deparado hallazgos de pintura parietal verifica la existencia de inmuebles de diversa naturaleza, públicos y privados, en las inmediaciones, cuyos restos han aparecido en posición normalmente secundaria en las excavaciones. Buena parte de los mismos se encuentran inéditos y sin un diagnóstico siquiera inicial, por lo que no resultan posibles ulteriores aclaraciones sin proceder a una autopsia detallada de los mismos, que excede los límites de este trabajo. Solamente tenemos constancia de los restos pictóricos publicados de la casa del Obispo, con las Musas datadas en la primera mitad del siglo I d.C., no muy lejanos espacialmente (Cánovas y Guiral 2007); y los del ya citado Club Náutico La Caleta (Fernández Díaz 2010), ambos correspondientes al tercer estilo pompeyano, y probablemente de época augusteo-tiberiana, lo cual convierte a estos restos de El Olivillo en especialmente interesantes por su cronología y por la escasez de documentación aún sobre pintura mural en la Cádiz romana.

\section{CONTEXTO ARQUEOLÓGICO DE LOS RESTOS DE PINTURA PARIETAL DE EL OLIVILLO}

La presencia de restos de pintura mural en el vertedero de El Olivillo constituye una de las cuestiones de interés en este yacimiento gaditano, máxime si tenemos en cuenta la escasez de este tipo de evidencias, bien conservadas y bien estratificadas, en otras excavaciones preventivas realizadas en la ciudad, tal y como hemos relatado anteriormente. Si bien estos se muestran descontextualizados de su posición original por hallarse dentro de un vertedero público, su cronología es clara y, además, si analizamos la dinámica urbana de la ciudad en dicha época, podríamos pensar en la posibilidad de que formaran parte de la decoración de algún edificio relacionado con la zona artesanal o productiva tal y como sucede en el caso de Carthago Nova (Fernández Díaz 1999: 2008). No obstante, a pesar de esta dificultad de adscripción edilicia y, por ende, funcional, 


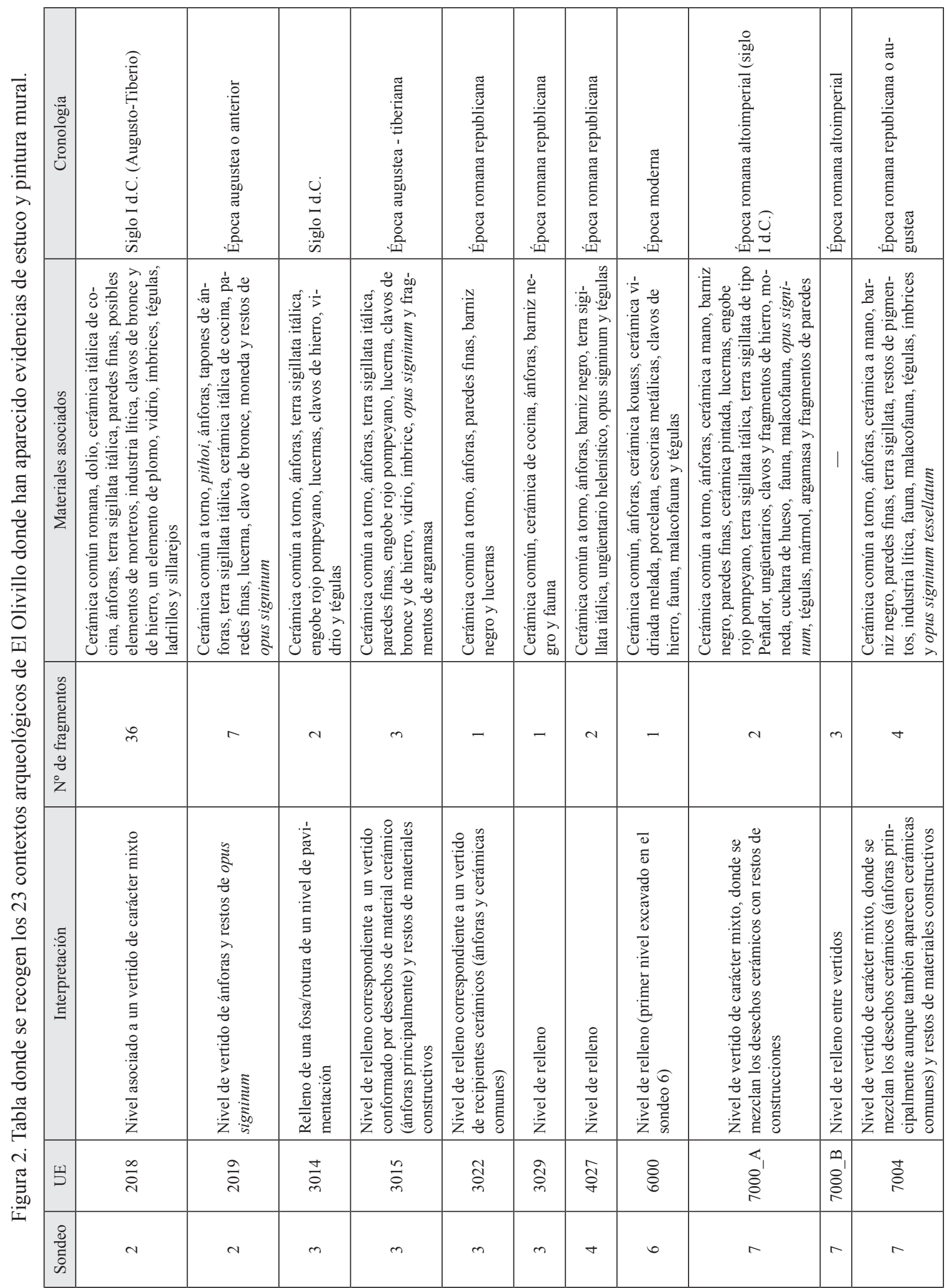




\begin{tabular}{|c|c|c|c|c|c|c|c|c|c|c|c|c|}
\hline 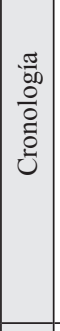 & 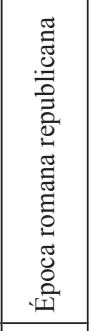 & 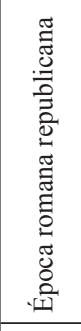 & 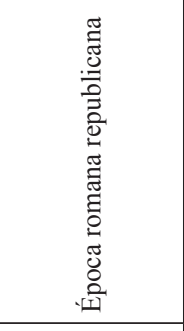 & 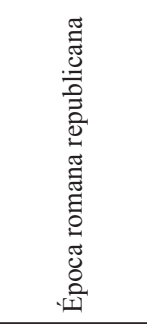 & 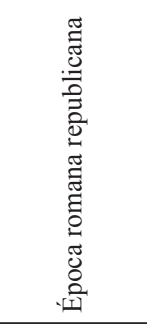 & 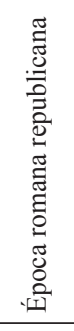 & 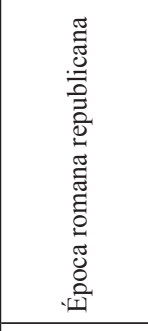 & 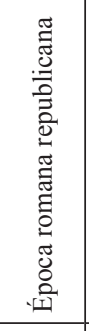 & 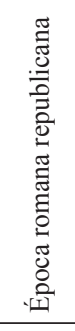 & 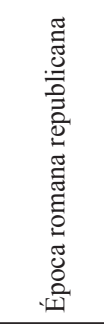 & 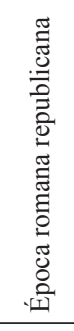 & 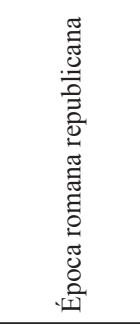 \\
\hline 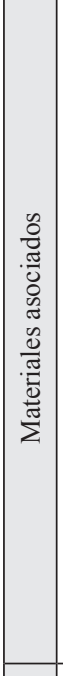 & 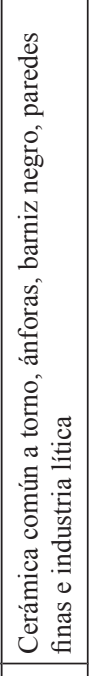 & 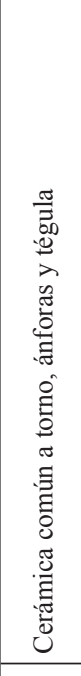 & 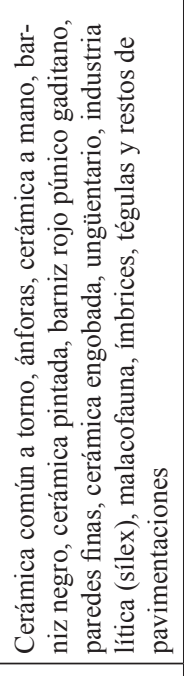 & 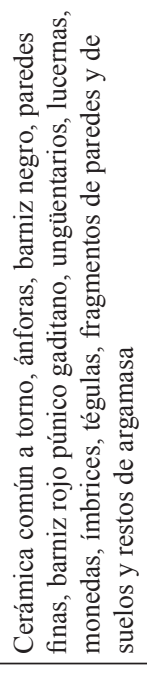 & 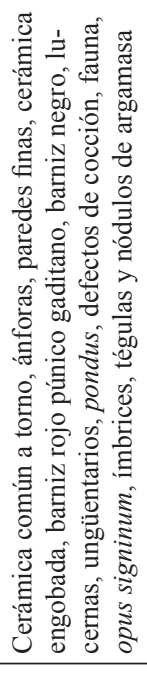 & 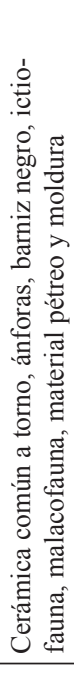 & 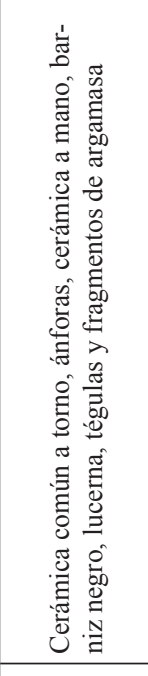 & 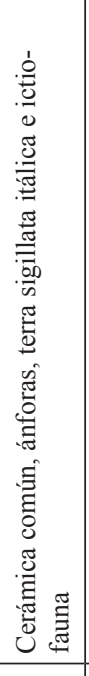 & 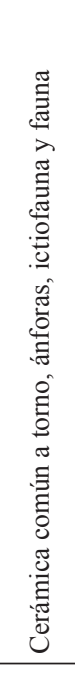 & 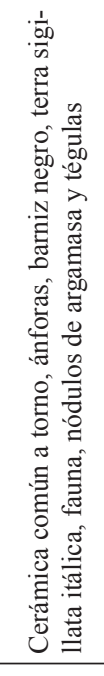 & 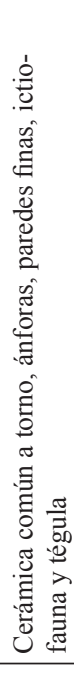 & 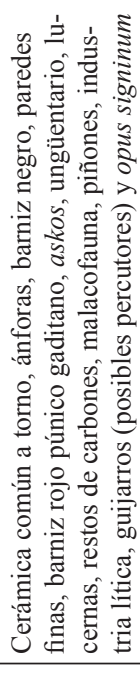 \\
\hline 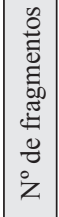 & - & - & - & $n$ & $\tilde{q}$ & $\nabla$ & $m$ & $N$ & - & $\stackrel{\infty}{n}$ & $m$ & - \\
\hline 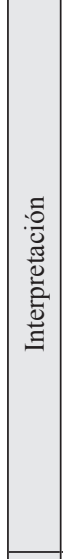 & 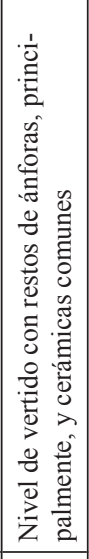 & 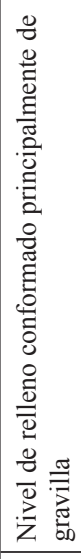 & 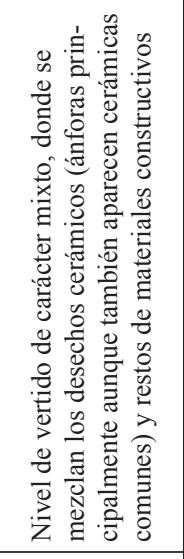 & 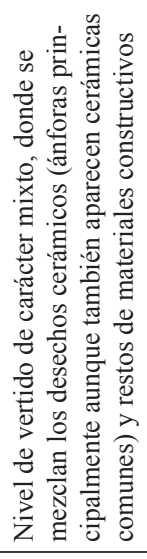 & 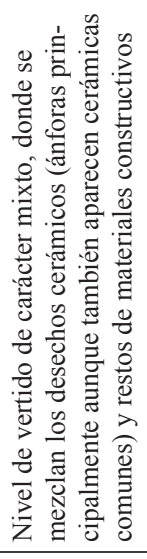 & 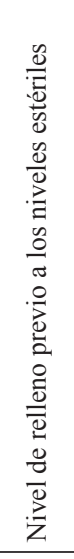 & 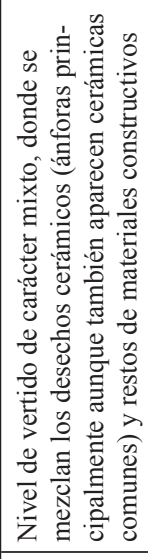 & 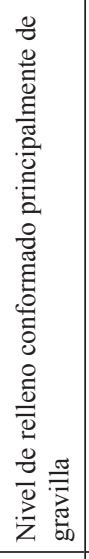 & 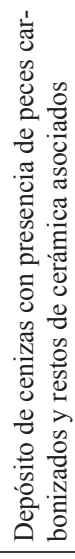 & 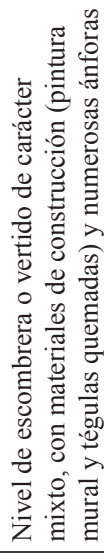 & 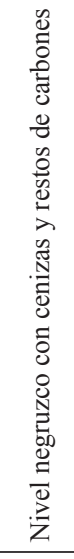 & $\begin{array}{l}\frac{0}{0} \\
\overline{0} \\
0\end{array}$ \\
\hline ) & $\stackrel{8}{\circledR}$ & $\stackrel{\circ}{\circ}$ & $\bar{\Omega}$ & $R$ & $\therefore$ & 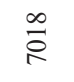 & $\therefore$ & $\therefore$ & $\stackrel{2}{2}$ & §̊ & ๙્ळે & ઠे \\
\hline$\stackrel{\Xi}{\Xi}$ & $r$ & $r$ & 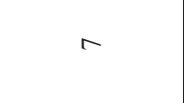 & r & $r$ & $r$ & 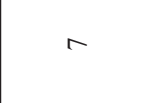 & $r$ & $r$ & $r$ & $r$ & $a$ \\
\hline
\end{tabular}




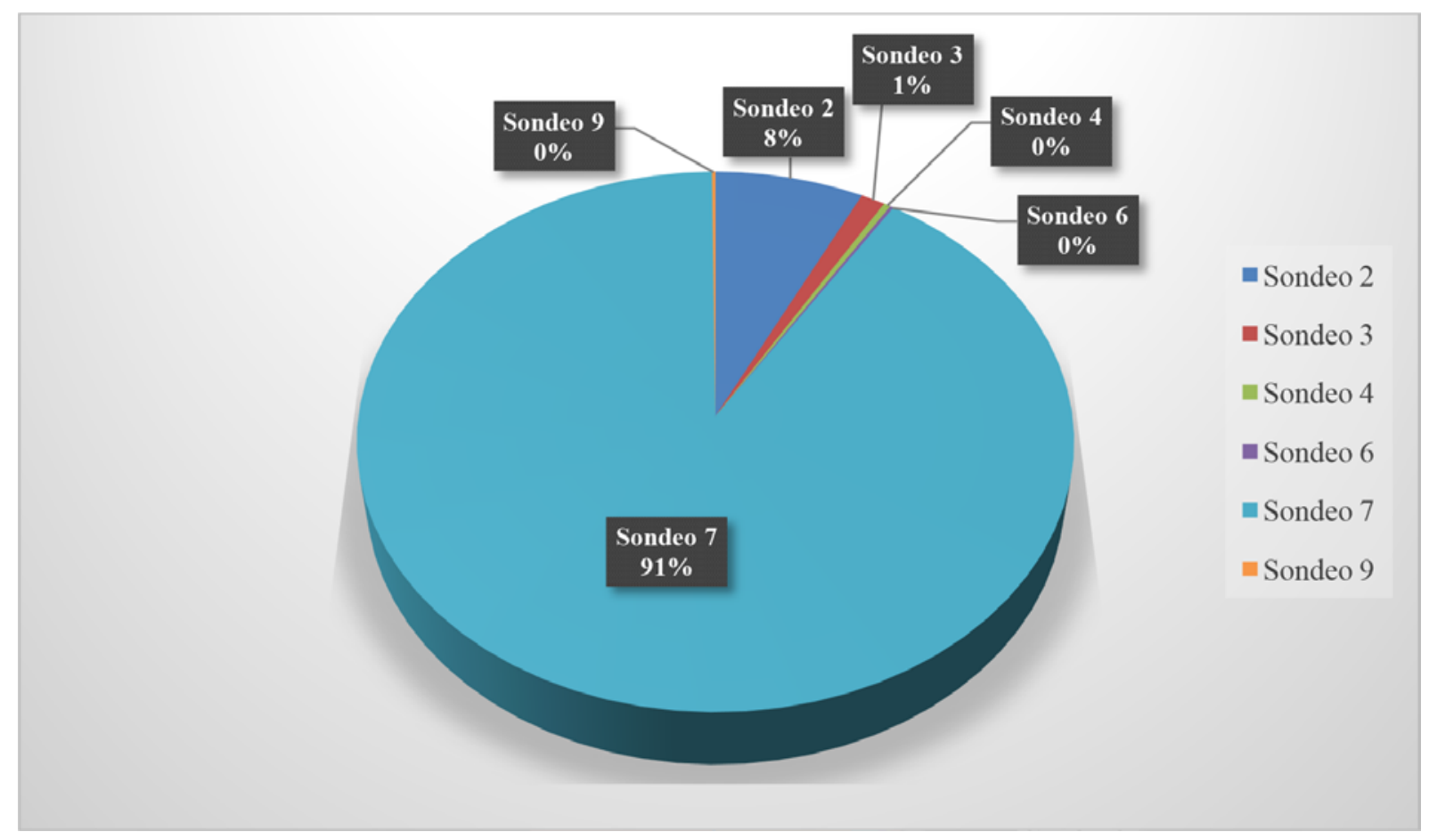

Figura 3. Gráfico con la representación de fragmentos de estuco y pintura mural de El Olivillo organizados por sondeos.

pasamos a introducir el contexto arqueológico en el que se encuentran.

Si bien la intervención puso de manifiesto la existencia de un yacimiento que presenta una cronología comprendida entre el siglo I a.C. y época moderno-contemporánea, lo que viene a señalar que esta zona presenta una ocupación hasta etapas recientes, tal y como se indica en la introducción, nos centraremos únicamente en aquellas que cuentan con restos pictóricos y que se circunscriben, según su análisis y el contexto material que los acompaña, entre el siglo I a.C. y I d.C., para desarrollar más adelante las de época tardorrepublicana, que son las que cuentan con fragmentos propios del primer estilo pompeyano.

En total han sido 23 los contextos arqueológicos donde han aparecido restos de estas características (fig. 2), los cuales aparecen repartidos por 5 de los 9 sondeos excavados: 2 en el sondeo 2 (UU.EE. 2018 y 2019), 4 en el sondeo 3 (3014, 3015, 3022 y 3029), 1 en el sondeo 4 (4027), 1 en el sondeo $6(6000)$, y 14 en el sondeo 7 (7000_A, 7000_B, 7004, 7006, 7009, 7011, 7014, 7016, 7018, 7023, 7024, 7025, 7028 у 7029).

El número total de fragmentos recuperados ha sido de 585, una cifra que deja entrever la importancia que tuvieron este tipo de descargas en el proceso de formación del vertedero, sobre todo en su fase romana republicana, tal y como hemos podido constatar en el sondeo 7 donde se han concentrado el $91 \%$ de los restos documentados (fig. 3), lo que se traduce en 531 fragmentos recuperados. Como puede observarse, a diferencia de este sondeo, en el resto del espacio excavado la aparición de evidencias de estuco y pintura mural se limita a determinadas unidades estratigráficas. Las razones que explicarían este alto porcentaje tendrían que relacionarse con cuestiones de tipo metodológico ya que en este sondeo la superficie total excavada ha sido de mayor extensión que en el resto de cortes estratigráficos, lo que ha permitido documentar una secuencia estratigráfica muy completa, que abarcaría todos los períodos identificados en El Olivillo, desde los niveles asociados al geológico hasta la ocupación moderno-contemporánea.

Los trabajos arqueológicos desarrollados en el sondeo 7 han resultado de vital interés para conocer la fase romano-republicana de El Olivillo, habiéndose identificado una serie de niveles de vertido con gran cantidad de materiales arqueológicos, que situamos desde el segundo cuarto de la centuria en adelante, es decir, 75-50/40 a.C. (Bernal y Vargas 2017: 36; Bernal y Vargas 2019). Sin lugar a dudas, el más importante de todos corresponde a la UE 7016 de donde proceden 433 fragmentos de pintura mural y estuco entre los desechos cerámicos de ánforas y cerámicas comunes, así 


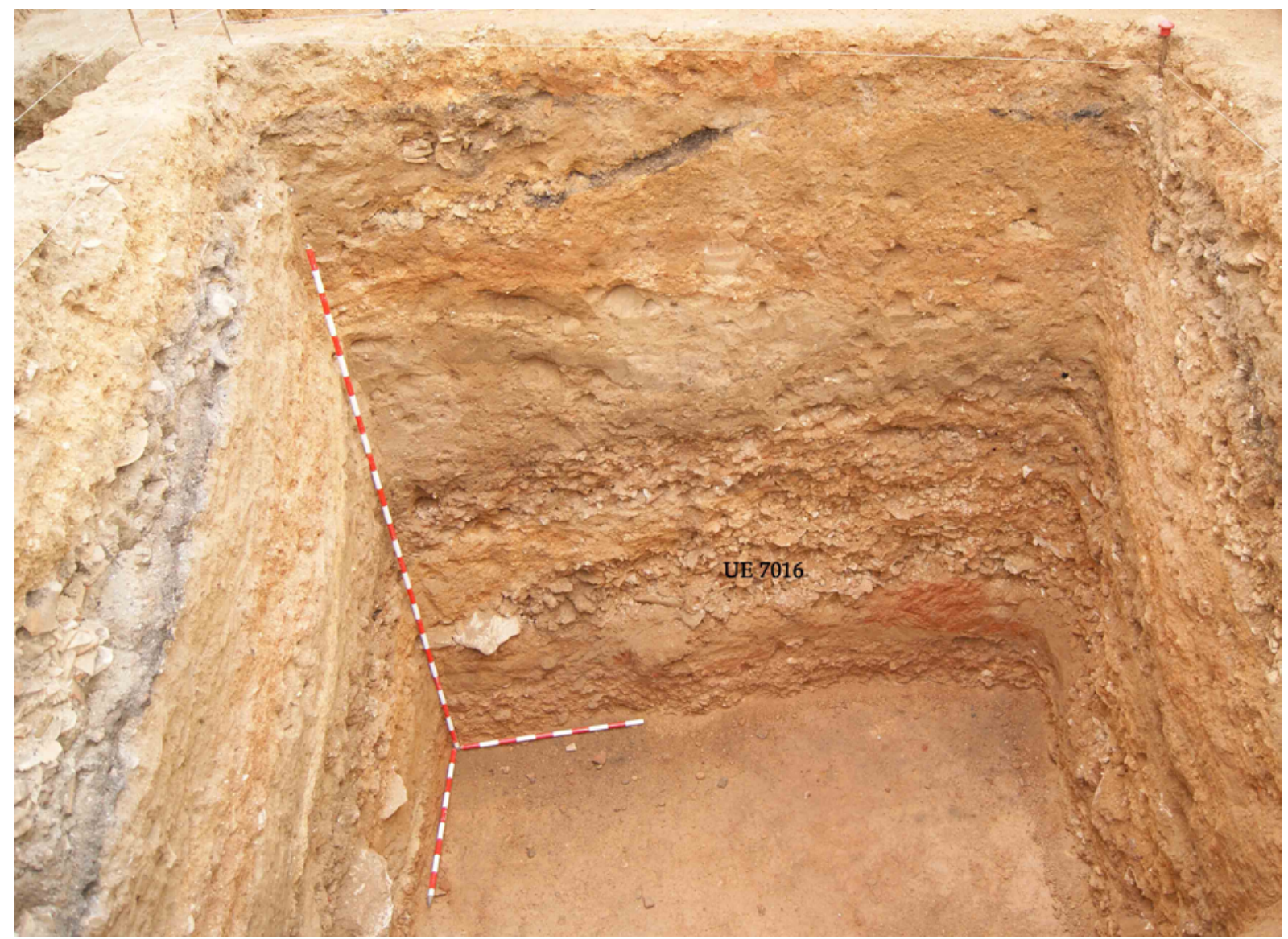

Figura 4. Perfil estratigráfico occidental del sondeo 7 con indicación de la UE 7016.

como de restos de materiales constructivos (fig. 4). Junto a esta unidad, hemos documentado otros vertidos de similares características donde su presencia es, sin embargo, totalmente anecdótica. Nos estamos refiriendo a las UUEE 7004 (3 fragmentos), 7006 (1 fragmento), 7011 (1 fragmento), 7014 (14 fragmentos) y 7023 (2 fragmentos), que constituyen niveles de relleno conformados principalmente por descargas haliéuticas $\mathrm{y}$, en menor medida, por vertidos de vajilla doméstica, habiéndose detectado una menor representación de escombros con respecto a la UE 7016. En este sentido, la presencia de estuco y pintura mural en los niveles que conforman el vertedero de El Olivillo es directamente proporcional a la mayor o menor cantidad de materiales constructivos documentados en los mismos. Por lo que respecta a la fase romana altoimperial (siglo I d.C.), la presencia de restos de pintura mural y estuco también es totalmente residual, habiéndose documentado 2 fragmentos en total, 1 de los cuales procede de la UE 7000_A -nivel de vertido mayoritariamente anfórico-y 1 de la UE 7000 B -nivel de relleno entre vertidos de ánforas.

A diferencia del sondeo 7, cuyos restos pictóricos trataremos más detalladamente en el siguiente apartado, en el resto del espacio excavado la aparición de evidencias de estuco y pintura mural se limita a determinadas unidades estratigráficas. Es el caso del sondeo 2 , donde se han documentado 43 fragmentos procedentes de 2 contextos arqueológicos localizados en la parte inferior de la secuencia estratigráfica y posiblemente pertenecientes a un momento cronológico similar (época augustea). El primero de ellos, la UE 2018, constituye un nivel de relleno donde la representación de restos cerámicos -vinculados a descargas de carácter pesquero-conservero y a vertidos domésticos- y de materiales constructivos parece ser equitativa. Bajo esta aparece un nivel de relleno mucho más heterogéneo y revuelto (UE 2019) conformado principalmente por descargas de ánforas, así como por vertidos de placas de opus signinum. 
En lo que se refiere al sondeo 3, los restos de estucos y pinturas murales están mejor representados en la secuencia estratigráfica si lo comparamos con el sondeo 2, habiéndose documentado 4 contextos arqueológicos con este tipo de evidencias, tanto de la fase republicana como altoimperial, aunque el número de fragmentos es considerablemente más bajo que en los sondeos anteriores ( 7 en total). Por lo que respecta a los contextos republicanos, ha sido la UE 3029 la que ha deparado un único fragmento por lo que es posible que corresponda a elementos procedentes de otros niveles de vertido, ya que la presencia de materiales de construcción es totalmente inexistente. De época romana altoimperial contamos con un número mayor de restos ( 5 fragmentos en total) procedentes de 2 unidades estratigráficas (3014 y 3015) fechadas en el siglo I d.C., la primera apenas relacionada con material constructivo, a diferencia de la segunda en la que se han documentado placas de opus signinum, nódulos de argamasa, ímbrices y ripios de piedra ostionera.

Los fragmentos que restan proceden de diferentes contextos arqueológicos del sondeo 4, 6 y 9, uno de los cuales pertenece a la fase romana republicana de El Olivillo, concretamente la UE 4027 que corresponde a un nivel de relleno con abundante presencia de materiales cerámicos -ánforas de tradición púnica, un ungüentario helenístico, cerámica de barniz negro y común a torno-, y en menor medida, constructivos -un fragmento de opus signinum, 6 tégulas y 2 trozos de paredes con restos de enlucido-.

\section{PINTURA Y ESTUCO DEL PRIMER ESTILO POMPEYANO}

Los restos pictóricos y en estuco pintado que pueden adscribirse al primer estilo pompeyano proceden del sondeo 7 , donde se han documentado una serie de niveles de vertido que datan del siglo I a.C. al siglo I d.C. Aunque en este encontramos fragmentos pictóricos en las UUEE 7000 A, 7000 B, 7004, 7006, 7011, 7013, 7014, 7016, 7018, 7023, 7024, 7025, 7028 y 7029, solo los pertenecientes a la UE 7016 (fig. 4), un relleno de carácter mixto en el que se mezclan desechos cerámicos con restos de materiales constructivos, pueden adscribirse claramente a dicho estilo. El resto, aun contando con un contexto cerámico de cronología republicana, a excepción de las unidades 7000 y 7000_A de cronología altoimperial, se encuentran en un estado muy fragmentario como para poder adscribirlos con seguridad a un estilo concreto.
En esta unidad se agrupan tres tipos de vertidos: los relacionados con la industria pesquero-conservera de la que se documentan un alto porcentaje de contenedores salsarios béticos y un raquis de atún; los de carácter doméstico, evidenciados por un gran número de vasijas de cerámica común a torno o de vajilla de mesa y restos de consumo alimenticio; y aquellos relacionados con materiales de construcción que pueden relacionarse con construcciones o reparaciones de edificios presumiblemente cercanos.

\subsection{Descripción y análisis técnico}

Todos los fragmentos analizados en este trabajo han sido clasificados en conjuntos en función de sus características técnico-estilísticas, de tal manera que se puedan diferenciar con claridad los distintos grupos de fragmentos que formarían parte de un mismo conjunto o pared. Para este estudio se han seguido las directrices de análisis de pintura mural establecidos dentro del proyecto al que se adscribiría dicho estudio y que aparece mencionado en los agradecimientos. Se trata de su documentación a través de fichas de análisis que contemplan datos de carácter contextual, técnico, estilístico y de conservación.

Conservamos un total de 433 fragmentos entre los que hemos podido diferenciar varios conjuntos: ocho cornisas molduradas en estuco con diferente sección, así como pintura mural correspondiente, probablemente a la zona inferior, media y superior del alzado de una pared.

De las cornisas molduradas en estuco, observamos fragmentos que parecen corresponder a ocho cuerpos distintos de cornisa, ninguno conservado íntegramente con su perfil completo. Dos de ellos presentan restos de un campo negro cuyas dimensiones totales desconocemos y el tercero se desarrolla sobre un campo azul, por encima del cual se conserva parte de la cornisa, aunque ninguna de ellas se asemeja al resto. Junto a estos, podemos contar al menos cuatro fragmentos más, pero que por su estado de conservación son imposibles de analizar. Se trata de una gran cantidad de cornisas que podrían responder a diversas estancias de un mismo edificio, sin embargo, los conjuntos pictóricos diferenciados no muestran una variedad tan grande como para poder confirmarlo.

De las mejor conservadas, la primera presenta un listel que sobresale de la vertical $0,8 \mathrm{~cm}$, seguido de un caveto de gran tamaño y de otro listel que forma dos picos salientes más o menos pronunciados, pero cuya 
continuidad se pierde hacia arriba mediante un tramo inclinado que se corta (fig. 5.1); la segunda presenta otro tramo inclinado que finaliza con un listel, seguido de un segundo tramo rematado por un bocel tras el cual parece desarrollarse uno de mayor tamaño, pero del que solo se conserva una parte debido a la rotura (fig. 5.2); de la tercera de las cornisas conservamos únicamente parte de la zona central, que presenta un caveto recto de 2,5 cm de altura al que sigue un bocel de $1,5 \mathrm{~cm}$, que da paso a un listel de $1 \mathrm{~cm}$, que sobresale de la vertical $0,5 \mathrm{~cm}$, tras el cual se desarrolla un tramo vertical cuyo final se pierde debido a la rotura de la cornisa (fig. 5.3); y por último, la cuarta, que conserva mayor desarrollo aun sin contar con el final de la misma. Esta presenta un tramo inclinado de $0,6 \mathrm{~cm}$, seguido de un listel con restos de pigmento rojo que sobresale $0,4 \mathrm{~cm}$ de la vertical y tiene una altura de $0,8 \mathrm{~cm}$; a continuación, se desarrolla una pequeña moldura cóncava o media caña a la que sigue un tercer tramo inclinado de $2 \mathrm{~cm}$ de longitud y que da paso a un pequeño listel que se une a un toro de $0,7 \mathrm{~cm}$, terminando en un cuarto de bocel del que se conservan $2 \mathrm{~cm}$ de longitud con restos de pigmento azul y una pequeña moldura cóncava tras la que se pierde el desarrollo hacia arriba (fig. 5.4). Si bien muestran algunos elementos que podemos observar en otros conjuntos de cornisas del primer estilo pompeyano como las de Azaila, el primero de los estudios realizados sobre este tipo de material en España (Mostalac y Guiral 1992), el estado de conservación nos impide poder establecer paralelos con otros ejemplares.

Al margen de estos fragmentos, encontramos otros cinco conjuntos, de los cuales el primero formaría parte de un friso, en este caso, de imitación de mármol giallo antico, aunque no descartamos la imitación de las vetas de madera rojas en posición vertical sobre fondo ocre. Dentro de este conjunto es posible diferenciar dos tipos de fragmentos debido a que presentan grosores distintos en las vetas, que en el caso más estrecho es de entre 0,2-0,3 cm (con algunas excepciones) (fig. 6.1) y en el caso más ancho ronda los $0,5-0,7 \mathrm{~cm}$ (fig. 6.2). En lo que respecta a estas, encontramos grosores distintos en diversos fragmentos que podrían estar indicando la pertenencia a la imitación de bloques de sillares y/o vigas diferentes, a lo que debemos añadir la presencia en algunos de ellos de una segunda cara que indica su grosor en la pared. Entre los fragmentos, el de mayor tamaño presenta unas dimensiones de $10 \mathrm{~cm}$ de altura total por $4 \mathrm{~cm}$ de profundidad mínima, así como $40,5 \mathrm{~cm}$ de longitud conservada y, tras un pequeño escalón de $0,5 \mathrm{~cm}$ de profundidad, el arranque en su extremo inferior de un campo de color blanco de $5 \mathrm{~cm}$ de altura conservada.
Todo ello sugiere la imitación de un bloque rectangular de aparejo en relieve de una modulación menor de 1 pie romano de altura por 2 pies de longitud aproximadamente como mínimo, dispuesto horizontalmente a lo largo del friso de una pared, tal vez en la zona superior de esta y que la separa de la zona media en la que se situaría un posible ortostato blanco del que desconocemos sus dimensiones.

El segundo de los conjuntos se corresponde con otro de los bloques de sillares imitado, de $11 \mathrm{~cm}$ de altura x $12 \mathrm{~cm}$ de anchura conservada, que podría componer un bloque de la hilada de un aparejo isódomo, tal vez la situada por encima del friso anteriormente descrito, en este caso en color rojo. Su modulación podría ser la de $1 / 2$ pie romano de altura por 2 pies de longitud mínima conservada, que presenta una superficie peor conservada, debido a las abrasiones propias del arrastre y contacto con otros elementos del vertedero (fig. 7).

En lo que respecta al tercero de los conjuntos diferenciados, conservamos un campo azul que podría formar parte de un sillar distinto del que solo se conservan $2 \mathrm{~cm}$ de campo y al que sigue un espacio de $4,7 \mathrm{~cm}$ con un rebaje respecto al campo azul de $0,5 \mathrm{~cm}$. Este podría estar marcando la separación entre el sillar y una cornisa, dado que el espacio parece demasiado ancho como para formar parte de la separación entre dos hiladas de sillares.

El cuarto está constituido por la imitación de un bloque de sillar de mármol blanco, presentando el mayor de los fragmentos conservados una altura total de 15 $\mathrm{cm}$ x $20 \mathrm{~cm}$ de longitud mínima conservada (fig. 8.1), por tanto, con una modulación algo menor al anterior y similar al primero, tal vez, medio pie de altura por 2 pies de longitud. Ello nos llevaría a situarlo en una zona más elevada de la pared que el primero, tal vez por encima del bloque de sillares dispuestos en aparejo isódomo de color rojo. Cabe señalar la presencia de un gran fragmento de cerámica incrustado en su mortero (fig. 8.2), lo que podría aportarnos información acerca del lugar al que estarían destinadas estas pinturas. Por último, el conjunto más numeroso está formado por fragmentos de fondo rojo que probablemente conformarían una hilada de grandes ortostatos que se situarían debajo del aparejo de sillares que hemos citado y que decorarían la zona inferior o zona media de la pared, y que dada la composición que muestra en su mortero que describiremos a continuación, se trataría de signinum pintado (fig. 9.1).

Todos los fragmentos presentan una capa pictórica superficial alisada, encontrando en algunos de ellos manchas resultado del posible deterioro sufrido por 

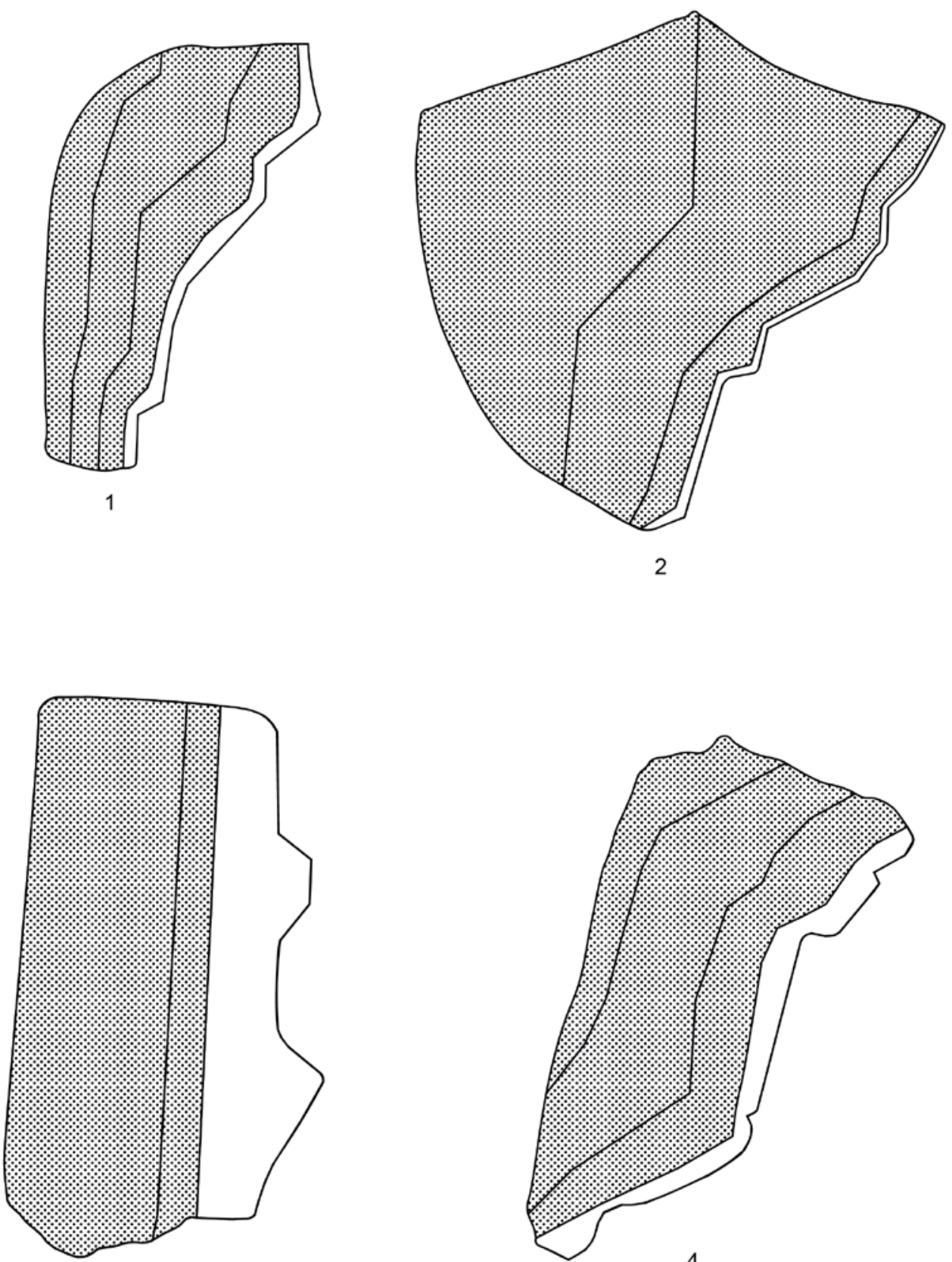

3
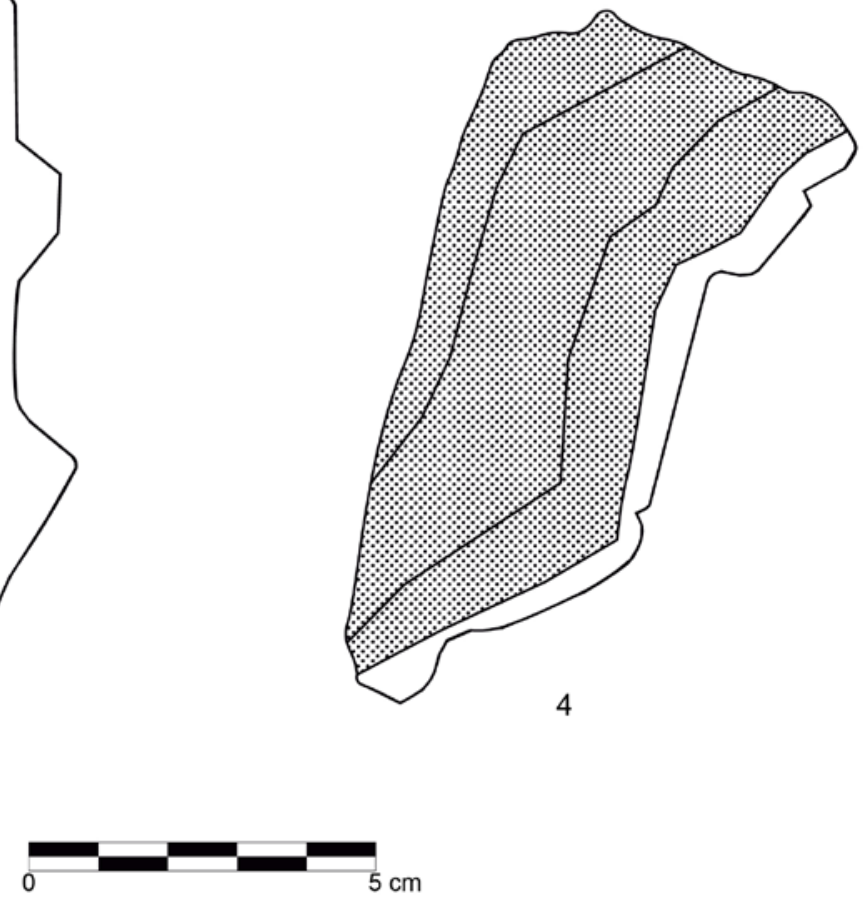

Figura 5. Conjunto de cornisas recuperadas dentro de la UE 7016. 


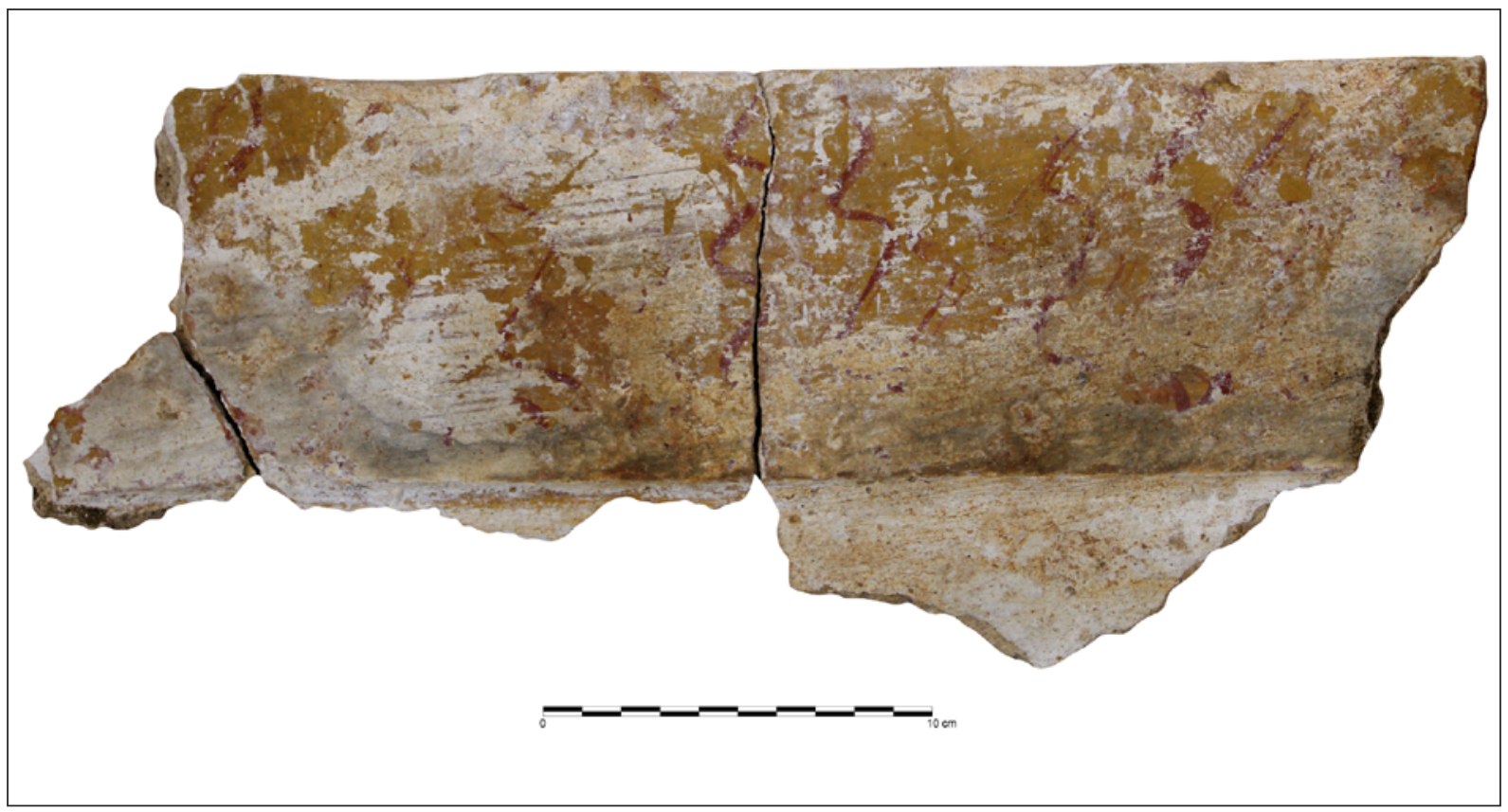

Figura 6.1. Fragmento de sillar de imitación de mármol giallo antico y/o viga de madera que muestra las vetas rojas de menor tamaño, así como el límite inferior del sillar o de la viga.

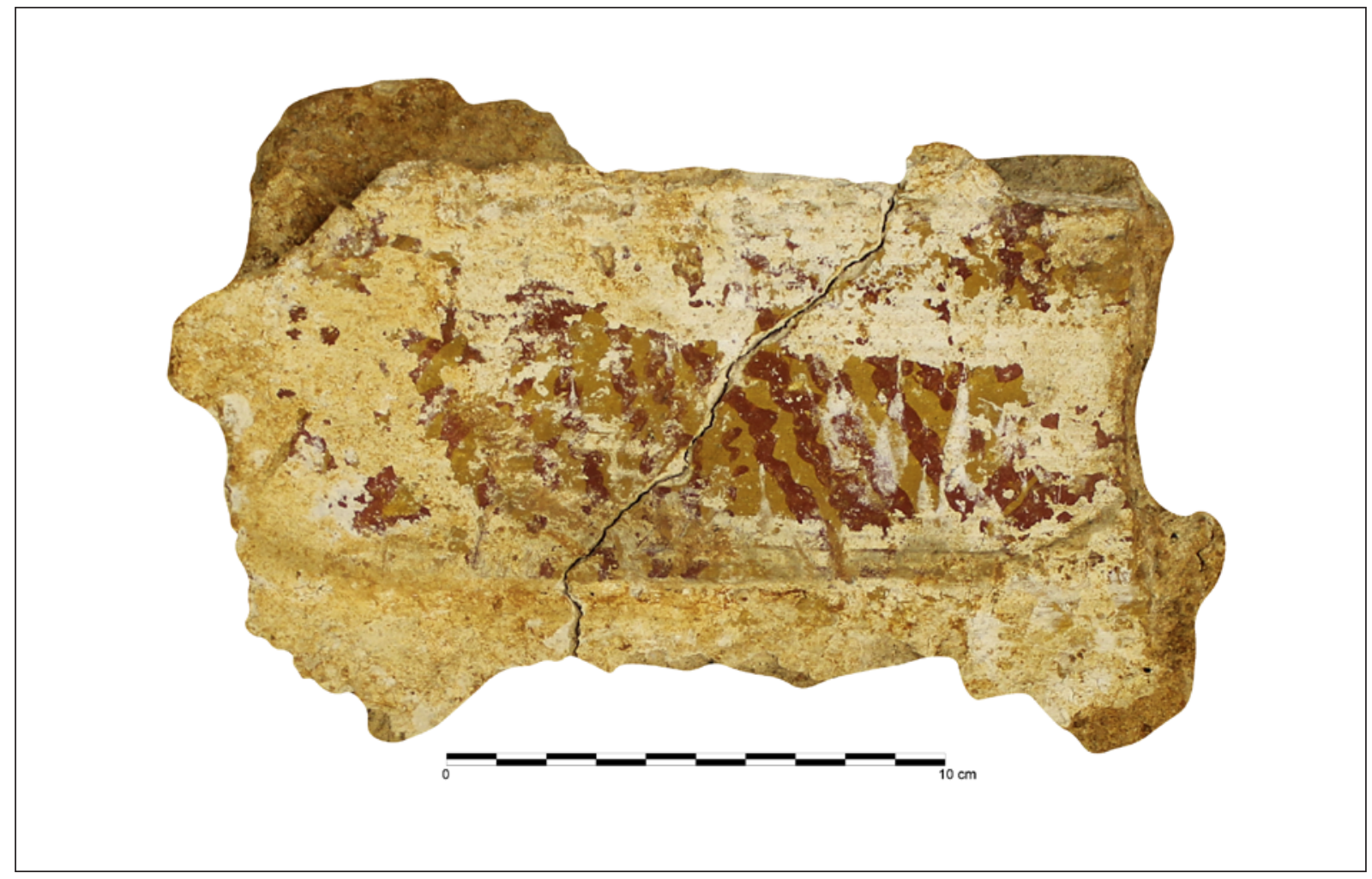

Figura 6.2. Fragmento de sillar de imitación de mármol giallo antico o de viga de madera que muestra las vetas rojas de mayor tamaño.

ISSN: 1133-4525 ISSN-e: 2255-3924 


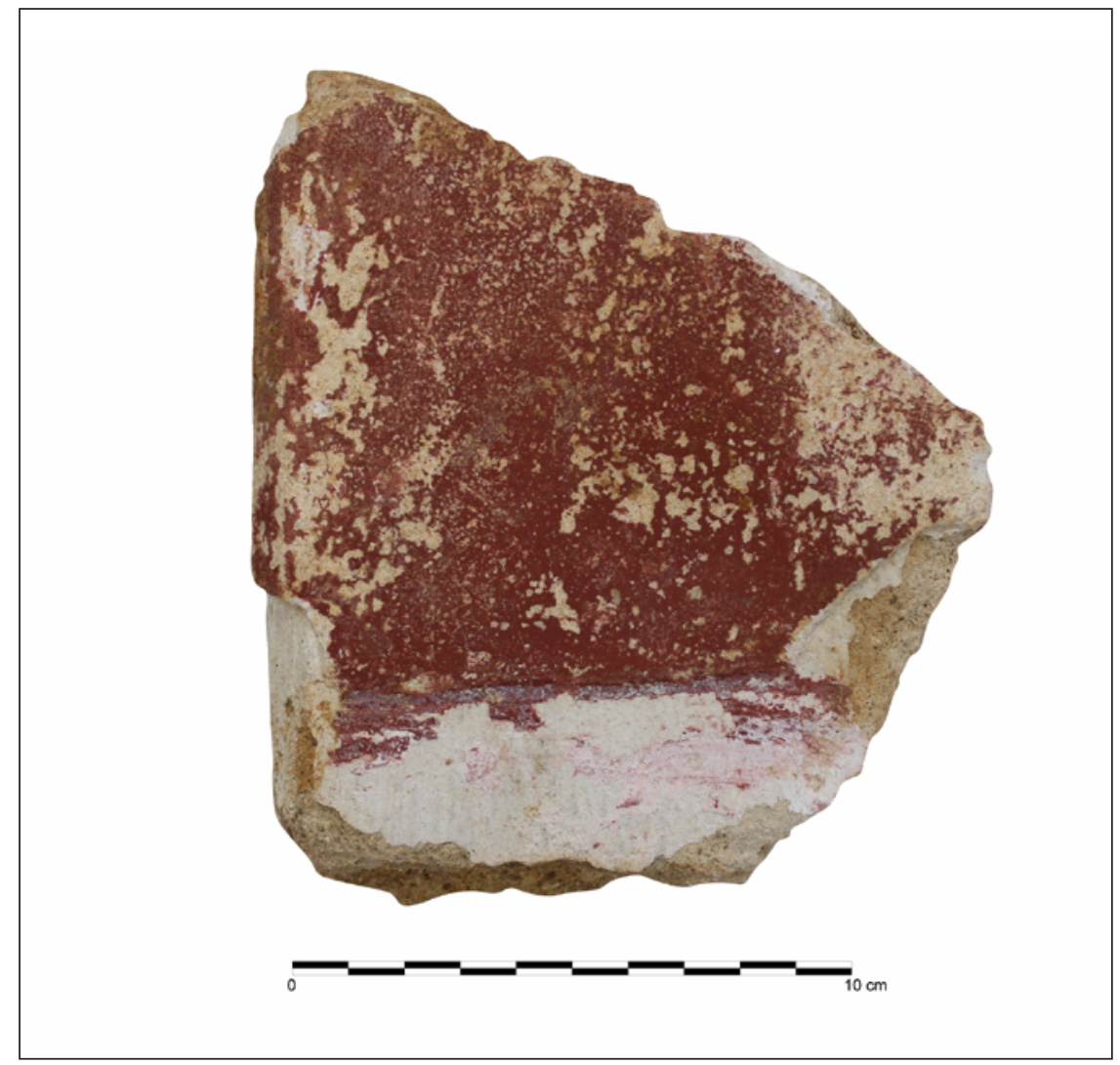

Figura 7. Fragmento de sillar de color rojo en gran parte desgastado por las abrasiones propias del contacto con el resto de elementos del vertedero. Podemos observar con claridad una de las esquinas del mismo en la parte izquierda del fragmento. los restos presentes en el vertedero y la humedad. La gran mayoría de ellos también presenta una capa blanquecina que se superpone a los pigmentos descritos y que podría responder a un repinte posterior, resultado de una posible reforma, un cambio de moda o gustos del propietario. Asimismo, con respecto al mortero que hay tras la capa del pigmento, cuyo grosor oscila entre 3 y 4,5 cm aproximadamente, conserva 3 capas: 0,5-0,8 $\mathrm{cm}$ de polvo de mármol la primera; $0,9-1,2 \mathrm{~cm}$ de arena muy tamizada, con gran cantidad de cal y presencia de piedras de no más de $1 \mathrm{~mm}$ de grosor la segunda; y 1,6$3,5 \mathrm{~cm}$ de mortero más arenoso y oscuro con abundante piedrecilla, restos de adobe y reverso en cañizo para la tercera capa que se caracteriza por ser menos compacta y de mayor fragilidad.

Con respecto a esto último, los análisis físico-químicos realizados mediante lámina delgada, Difracción de Rayos y SEM, a los que se han sometido los morteros de estos fragmentos de imitación de mármol blanco, rojo y giallo antico o imitación de las vetas de madera, han diferenciado una capa de $0,5-0,8 \mathrm{~cm}$ con un porcentaje de $85-95 \%$ de dolomitas, uno de los minerales que conforman las calizas. Se trata de un dato que resulta de especial interés dada la mención que las fuentes hacen de la utilización de polvo de mármol para la realización de morteros adecuados para la decoración pictórica de los edificios (Vitr. VI, 3). La presencia de este mineral en los distintos fragmentos analizados nos lleva a pensar que todos ellos pertenecieran a un mismo conjunto.

Asimismo, el análisis de los pigmentos mediante Difracción de rayos X practicado en los fragmentos de imitación de giallo antico o de las vetas de madera y los fragmentos rojos, arrojan como resultado la presencia de una pequeña cantidad de hematites $\left(\mathrm{Fe}_{2} \mathrm{O}_{3}\right)$, un óxido de hierro de color rojo pardo, dentro del pigmento rojo, por lo que descartamos la presencia de rojo cinabrio. En el caso del color amarillo, se ha detectado la presencia de goethita $\left(\mathrm{Fe}^{3} \mathrm{O}(\mathrm{OH})\right)$, un oxihidróxido de hierro cuyo color oscila entre un color pardo amarillento y amarillo ocre. Por otra parte, para el caso del fragmento con pigmento azul, dada la baja cantidad de pigmento conservado no ha aportado datos sobre ningún mineral distinto. En el caso del fragmento de imitación de mármol blanco, el análisis de la capa pictórica tampoco ofrece datos más allá de los ya extraídos mediante el análisis del mortero, por lo que podemos determinar la 
Figura 8.1. Superficie pictórica de unos de los fragmentos de imitación de mármol blanco.

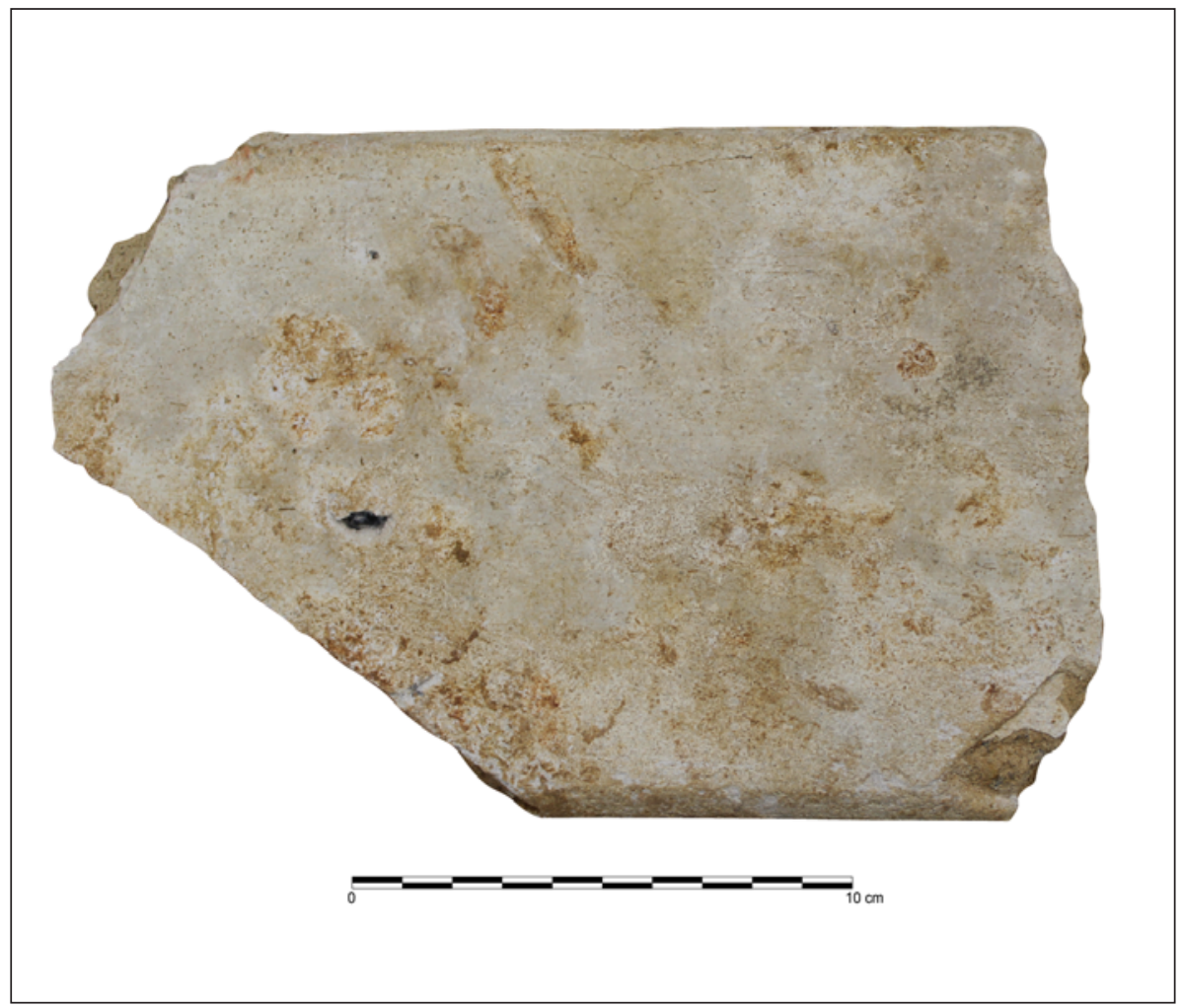

Figura 8.2. Reverso del fragmento anterior en el que se puede observar la incrustación de fragmentos de cerámica de gran tamaño, posiblemente con el objetivo de reducir los efectos de la humedad al hallarse estos conjuntos en alguna estancia cercana o en relación con el agua.

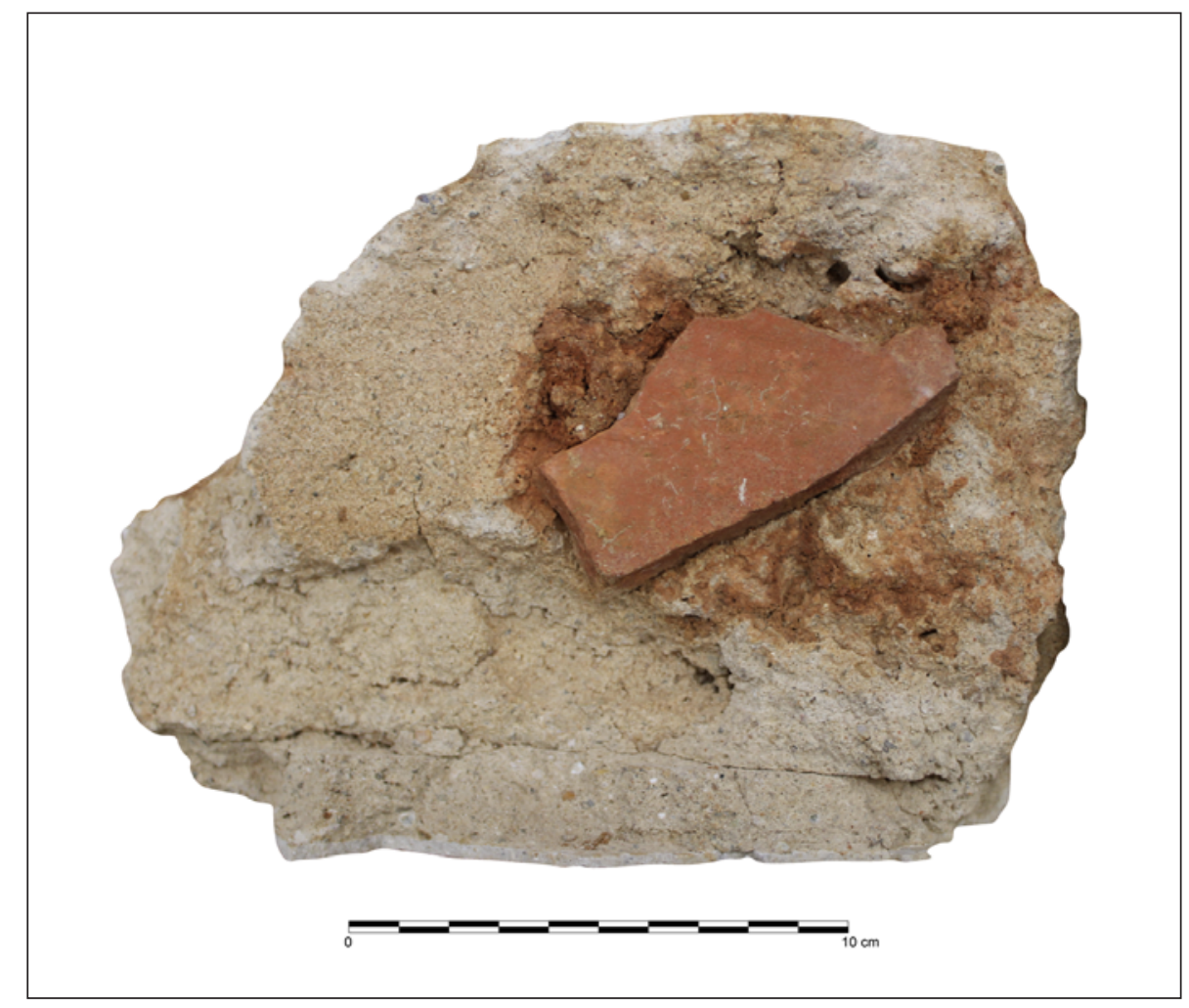


posibilidad de que la dolomita también fuera empleada en su momento para la ejecución del pigmento blanco.

En el caso del último de los grupos, la composición del mortero presenta unas particularidades que lo diferencian claramente del resto de los grupos arriba citados, estando formado por una primera capa de mortero con gran cantidad de cerámica machacada de mediano tamaño, seguido por una capa de conglomerado de arena de playa y restos de conchas (fig. 9.2). Tanto una como la otra, son particularmente interesantes, pues la primera nos lleva a pensar que se trate en realidad de opus signinum o el denominado cocciopesto por los italianos, pintado de rojo, y la segunda, demuestra la utilización como mortero de materiales locales propios de la zona.

Finalmente, en el reverso, predomina el sistema de sujeción en cañizo que, aunque es propio de un sistema de trabazón de techo, se localiza también en algunos alzados, pudiendo servir incluso como un indicativo cronológico, si pensamos que en esta ubicación su uso podría ser más antiguo. Las improntas del cañizo dejan ver la existencia, en su momento, de haces de cañas cuyas dimensiones podrían haber sido de entre 1 y $2 \mathrm{~cm}$ de anchura y $16 \mathrm{~cm}$ de longitud mínima en los fragmentos de mayor tamaño, conservando algunos de ellos restos de adobes rojizos en su interior que podrían formar parte de los muros a los que estuvieron adosados, así como grandes fragmentos de cerámica como en el caso del fragmento de imitación de mármol blanco.

\subsection{Análisis estilístico}

Para llevar a cabo este análisis, en primer lugar, debemos introducir las características y desarrollo del primer estilo pompeyano al que pertenecería nuestro conjunto. Este ha sido denominado como de incrustación, de mampostería o estilo arquitectónico, consistente en la reproducción, mediante el modelado o relieve en estuco y la utilización de colores vivos, del aparejo real -opus quadratum, aparejo isódomo o almohadillado- utilizado en la arquitectura pública y religiosa de donde procede el esquema compositivo, que, a su vez, sigue modelos arquitectónicos griegos de finales del siglo V y principios del IV a.C. (Mau 1882: 17). En este sentido, la mayoría de autores que se han especializado en su estudio, coinciden en considerar este tipo de revestimiento en relieve como un recurso para ennoblecer el aparejo usado en la construcción, para cubrir las imperfecciones de la estructura como adelantaba Borda (1958: 5-7), definiéndolo incluso como originario de la arquitectura clásica más que de la pintura (Dörpfeld 1911: 52; Beyen 1938; Bruno 1969: 308; Guillaud 1990; Strocka 1996; Barbet 2009).

Pero esta idea de una representación directa en estuco de formas arquitectónicas reales, ha contribuido a interpretaciones problemáticas en cuanto a su significado en la decoración de ambientes privados, pues algunos investigadores creen que su intención es asociar el espacio privado (o semiprivado) de la casa con los espacios públicos de la vida política (Leach 2004: 61-63; Wallace-Hadrill 1994: 25-26; Clarke 1991: 40; Laidlaw 1985: 307 y ss.). En estos últimos años, incluso, se debate su intencionalidad, es decir, su función no como una imitación o sustituto directo de bloques de sillería de piedra o mármol, sino como un tipo de decoración interior que formaba parte de una tradición madura de moldeado de estuco y pintura en el período helenístico (Ehrhardt 2012: 110-111; McAlpine 2014: 87), que trataba de popularizar y honrar la cultura de dicho período (Bruno 1969; Leach 2004: 62). Si tenemos en cuenta esto último, y el hecho de que el primer estilo de la etapa republicana, muy similar en los interiores domésticos y los exteriores de la arquitectura pompeyana, continúa su tradición mucho después que este estilo pasara de moda (Mols 2005), confirmaría que estamos ante un estilo y no un período concreto, es decir, un estilo que a pesar de ser omnipresente entre el siglo III y el 80 a.C., también se utilizó con posterioridad, dejando de lado una práctica que ha sido fuente de confusiones y a veces de errores (Laidlaw 1993: 234). No obstante, a diferencia de otros ejemplos, incluso pompeyanos, en este de Cádiz se deja ver que, si bien la piedra decorativa era un componente importante en esa tradición, la representación precisa de tipos específicos de piedra -como podría ser el caso de la imitación de marmor numidicum - era tan importante como la variedad, vivacidad y creatividad.

Este primer estilo puede dividirse en dos modalidades diferentes en base a sus características y áreas de difusión: el denominado estilo estructural o Masonry Style, de procedencia griega, documentado a partir de finales del siglo V e inicios del IV a.C. en el Ágora de Atenas, en diversas viviendas de Pella (Macedonia) o de Gela y Morgantina, en el área apula, así como en las viviendas de los mercaderes adinerados de Delos de origen italocampano a partir del siglo II a.C., por tanto, con un claro ámbito de empleo en el Mediterráneo Oriental; y, por otro lado, el primer estilo propiamente pompeyano, de base helenística, pero de origen local en la zona campana, estando presente en la casa del Fauno (VI 12, 2-5) o la casa de Sallustio (VI 2, 4) en Pompeya 
Figura 9.1. En la imagen puede apreciarse la capa pictórica del fragmento en color rojo, así como la composición del mortero que sigue bajo esta, donde se distinguen diversos fragmentos de cerámica de varios colores.

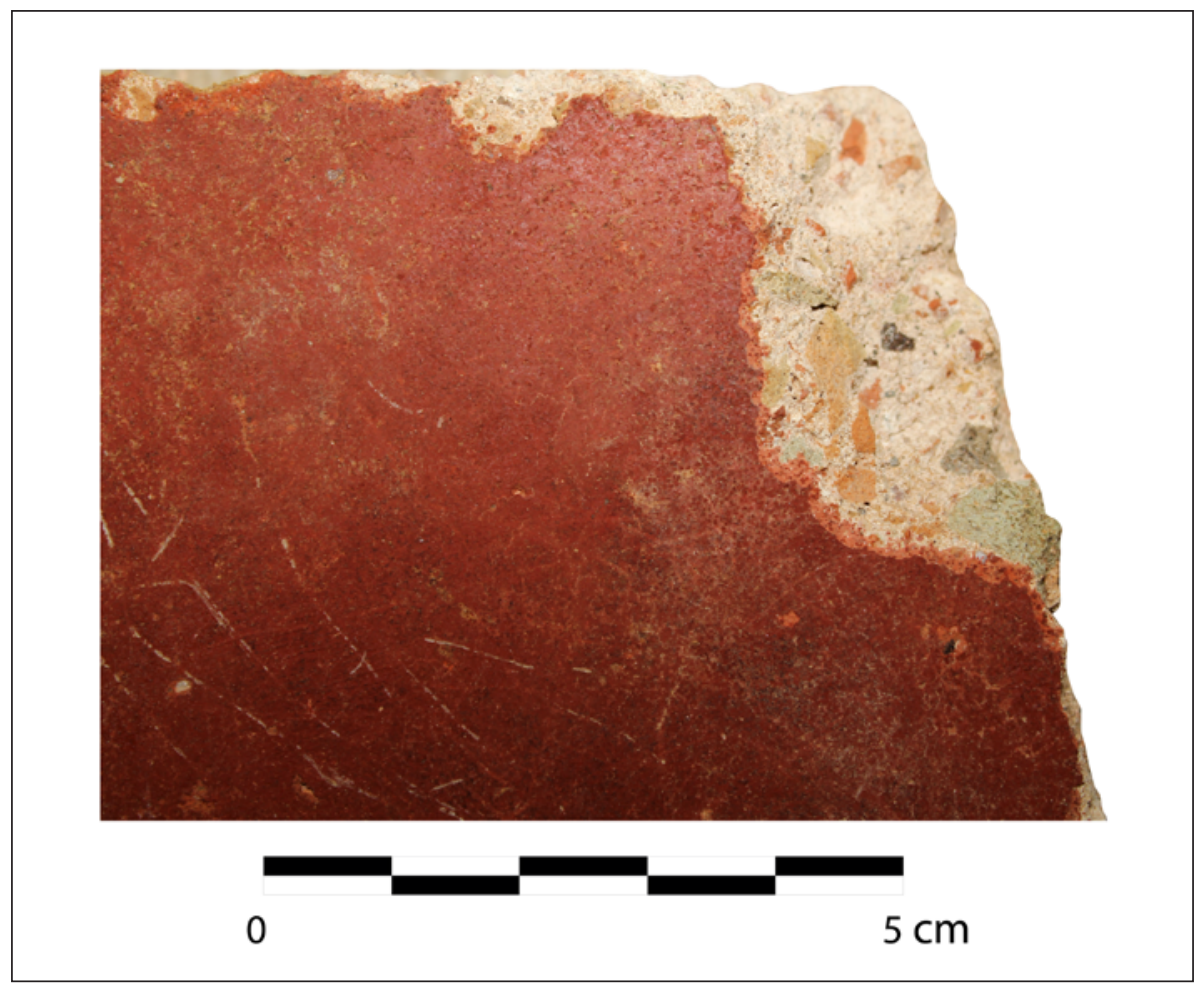

Figura 9.2. Sección de uno de los fragmentos del conjunto de pintura sobre cocciopesto en el que podemos observar claramente la composición de la capa de mortero con cerámica machacada a la que sigue una capa de conglomerado de arena de playa, cantos rodados y conchas.

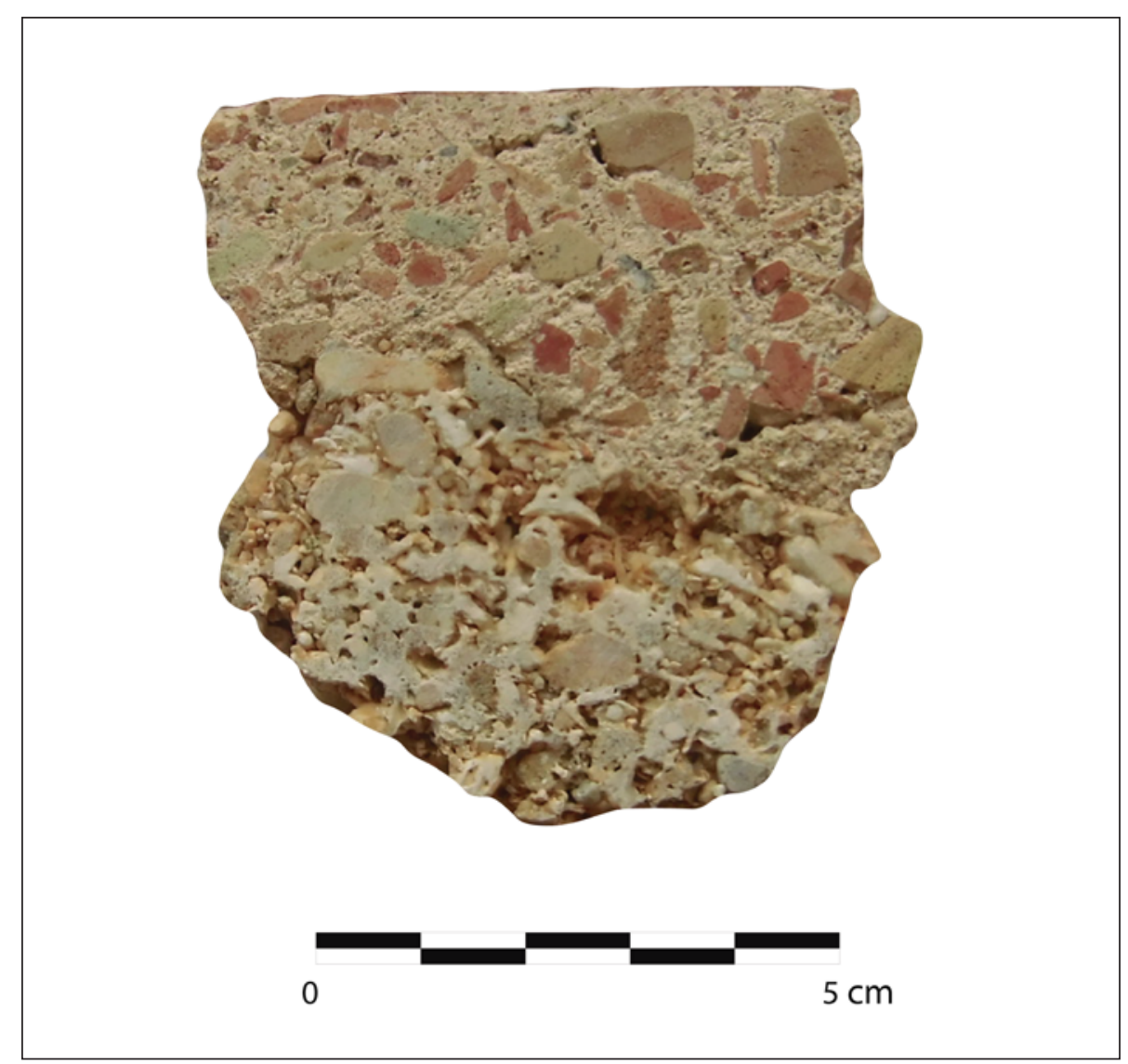


(Bruno 1969: 311), así como en la casa Samnita de Herculano (V, 1-2) (Borda 1958: 13-14), donde, siguiendo las líneas generales arriba planteadas, comienzan a introducirse variantes significativas que lo convierten en el estilo regional a partir del que Mau realiza su tipología y que, en el caso de este estilo, se ha dividido a posteriori en tres tipos diferentes según su disposición en los ángulos de las paredes y que han evolucionado desde la intención de imitar una construcción real hacia su simplificación gradual en un patrón pseudoisodómico de simetría continua y, finalmente a una simetría cruzada entre los paneles anchos y los más pequeños (Laidlaw 1993: 234).

De esta manera, si en el primero, de origen oriental, prima la policromía, de colores negro, rojo y amarillo imitando diversos tipos de mármol, alabastro o conglomerado, y también decoraciones de meandros, motivos florales o escenas figuradas aplicados a una pared que se concibe en tres niveles, contando en su parte inferior con un zócalo sobre el que se apoyan ortostatos que siguen las leyes de la estética del período clásico griego (Laidlaw 1985: 35-37), un friso compuesto por un aparejo isódomo que marca el límite entre la zona baja y la zona alta del muro, caracterizada por una larga banda continua formada por un friso de figuras o de rectángulos encuadrados en un sistema de molduras, muy bien representado en Delos (Alabe 1994: 8-15); en el segundo, el propiamente pompeyano, su desarrollo local lleva a que se produzcan cambios en la policromía, la distribución y la presencia de determinados elementos, no apareciendo aquí las escenas figuradas de forma generalizada que si encontramos en el estilo estructural griego, ni la composición cerrada sobre cada uno de los muros de un espacio determinado (Laidlaw 1993: 235).

Las paredes del ámbito romano-campano constan de elementos constantes que permiten dividir la pared en tres zonas: una zona baja o zócalo, totalmente lisa o con un rodapié y que alcanza hasta $1 \mathrm{~m}$ de altura; la zona media, formada por una banda de paralelepípedos o grandes ortostatos en relieve dispuestos en sentido longitudinal que en ocasiones suele ir rematado por una moldura o cornisa; y una zona superior compuesta de campos en forma de sillares o bloques escuadrados que pueden estar representados en relieve o únicamente incisos con el fin de simular el aparejo isódomo, y que suele quedar rematada por diversos cuerpos de cornisas, generalmente de estilo jónico, con decoración denticulada propia de la época, siendo un ejemplo claro el que encontramos en el cubiculum 3 de la casa del Centauro en Pompeya (VI 9, 3/5) (Laidlaw 1985: 25; Barbet 2009: 25). El alzado adquiere así una nueva categoría plástica y cromática en el programa decorativo-ornamental de un edificio, imperando la imitación en la arquitectura privada de fachadas o interiores de la arquitectura pública.

La llegada de este estilo a la península itálica debemos basarla en el hecho de que, en el citado período, Roma tiene en su poder la mayor parte del mundo mediterráneo, lo que le permite un intercambio de productos, gentes e ideas con el Oriente helenístico. El desarrollo de estas relaciones devendría en la adaptación de conceptos culturales de entre los cuales la luxuria supondría la causa de la profunda revolución artística que sufriría Roma, adaptada al carácter propio de las gentes que habitan la Península Itálica (Torelli y Marcattili 2010: 40). No obstante, debemos recordar que el primer estilo pompeyano no constituye la primera muestra de pintura parietal en el mundo romano, tal y como atestigua el hallazgo en la Insula I 5 de Pompeya de un conjunto fechado a finales del siglo IV e inicios del III a.C., lo que confirma la existencia de un estilo precedente sin afinidad con el primer estilo (Brun 2008; Seiler 2011: 499). En definitiva, su cronología en la Península Itálica abarca aproximadamente desde el siglo III hasta el 78 a.C., fecha esta última en la que contamos con un grafito de la Basílica del Foro de Pompeya que nos marca el terminus ante quem al ser la decoración sobre la que se inscribe anterior a este. Junto a este dato debemos destacar la asociación del primer estilo pompeyano a pavimentos de opus signinum teselados que se localizan en Italia de forma abundante en estructuras datadas a finales del siglo II a.C. o principios del siglo I a.C. (Becatti 1961: 253-267; Morricone 1971), al igual que sucede en diversos yacimientos de las provincias del Imperio y que, en ocasiones, permite matizar las cronologías de los conjuntos pictóricos.

Al margen de la cronología señalada, y aunque el primer estilo pompeyano llega a perdurar hasta finales del siglo I d.C. como una vieja moda que muchos propietarios solicitaban para ennoblecer sus propiedades y a su familia, simbolizando la reafirmación de viejos valores conectados con conceptos propiamente romanos como son los de gravitas y mos maiorum (Laidlaw 1985: 15-17), fuera de la península itálica y en las provincias occidentales, el primer estilo pompeyano aparece documentado en contextos que van desde mediados del siglo II hasta el primer tercio del siglo I a.C. y en algunas ciudades del sur de la Galia como Marsella, Glanum y Lattes, debido en gran parte a que son, durante mucho tiempo, tierras helenizadas por comerciantes griegos (Barbet 1987: 7). Debemos señalar que algo similar debió ocurrir en Hispania, dado 
que algunos de los yacimientos que citaremos a continuación constituyeron en su momento importantes enclaves, como el caso de Carthago Nova que, si bien adquiere entidad como ciudad portuaria en época romana, ya era conocida por los comerciantes griegos, tal y como atestigua la presencia de epigrafía y producciones cerámicas de origen oriental (Abascal y Rama1lo 1997; Lara et al. 2009; Ramallo y Valderas 2010).

En segundo lugar, hemos de mencionar los posibles paralelos encontrados en Hispania, de los que conservamos varios ejemplos en Aragón, como son el de Azaila, datado en el primer cuarto del siglo I a.C., o los de Contrebia Belaisca y Caminreal, con una cronología similar (Guiral y Mostalac 1987; 1993; 2011), así como un techo casetonado proveniente de Valdeherrera (Guiral e Íñiguez 2015) y datado en la segunda mitad del siglo II a.C. Junto a estos, encontramos un caso distinto a los mencionados; se trata del hallado en la ciudad celtibérica de Sekeiza/Segeda (Belmonte de Calatayud), que presenta grandes similitudes con aquellas producciones que manifiestan claros influjos helenísticos (Guiral y Mostalac 2011). Desconocemos si estas decoraciones eran producto de un taller de la costa que se desplaza también al interior aprovechando las vías fluviales, pues se conservan restos de dicho estilo procedentes de la costa catalana, concretamente del ambiente 3 de la villa de Can Martí en Samalús (Vallès Oriental), de los que no hay reproducción gráfica (Aquilué y Pardo 1990), y los hallados en el castellum de Can Tacó. Fuera de la región aragonesa, también contamos con el conjunto identificado en Carthago Nova y procedente de la plaza del Hospital, así como con los escasos restos hallados en la domus de los Delfines (Fernández Díaz 1999; 2004; 2008).

En el yacimiento de Azaila, al norte de la provincia de Teruel, se identificó una etapa de claro influjo itálico de la que se conserva decoración pictórica en el templo in antis y en la vertiente sur de la acrópolis. En el primer caso, gracias a la documentación de J. Cabré (1925: fig. 13-14) y a los estudios posteriores de C. Guiral y A. Mostalac (1987: 233-235) sabemos que las paredes de la cella estuvieron decoradas con un aparejo isódomo, quedando estructuradas probablemente por un zócalo liso, una zona media con imitación de sillares almohadillados y una zona superior que podría articularse mediante dos cuerpos de cornisas separados por una faja o banda (fig. 10.1). En el segundo, se recuperaron fragmentos de imitación de mármol, destacando la imitación de alabastro con franjas concéntricas ramificadas e imitaciones de brechas asociadas a las de alabastro que tienen paralelos en la casa del Fauno
(VI 12, 2-5) y en la casa del Championnet (VIII 2, 1-3) de Pompeya, respectivamente. Junto a esto, se cuentan además fragmentos de cubos en perspectiva en verde, blanco y negro que permiten precisar la cronología de ambos conjuntos en torno al primer cuarto del siglo I a.C., dado que la destrucción de la ciudad se fecha entre los años 76-72 a.C. (Guiral y Mostalac 2011: 601602). Si bien la funcionalidad del primer conjunto es distinta al ser un edificio público, el conjunto de El Olivillo compartiría con este la probable presencia de un zócalo liso, en este caso de opus signinum pintado, una zona media de ortostatos, que aquí es de color blanco, así como una faja o banda también almohadillada y de color blanco, que, en esta ocasión, desconocemos si se trata de separación de dos cornisas molduradas o del aparejo isódomo. Del segundo ejemplo, por su parte, encontramos similitudes en la imitación de una brecha.

En el caso del yacimiento de La Caridad, en Caminreal (Teruel), los restos pictóricos que se relacionan con el primer estilo pompeyano corresponden a la casa de Likine en la insula I, en concreto a los cubicula 4 y 13. Si del primero se conserva únicamente la zona del zócalo, pintado en negro y con representación de medias columnas en estuco de color rojo, un modelo similar al identificado en Contrebia Belaisca (Guiral y Mostalac 1993: 370-374); del segundo, sobre el pavimento, se localizan las improntas de las semicolumnas que estuvieron adosadas a las paredes, siguiendo el mismo modelo que los ya citados (Guiral y Mostalac 2011: 603-604); no obstante, en referencia a estos últimos, si bien en un primer momento fueron señalados como muestra del primer estilo, es debido a lo fragmentario de los datos aquí señalados que se clasificó posteriormente como una decoración de monocromías o bicromías, sin poder defenderse como un primer estilo. Como podemos observar, estamos ante espacios privados con una función concreta, la de cubicula, que en este estilo suelen presentar elementos arquitectónicos que compartimentan el espacio. Aunque en nuestro caso contamos con una información parcial producto de su hallazgo en un vertedero, probablemente podríamos descartar la correspondencia de los fragmentos analizados a este tipo de estancia.

En lo que respecta a los restos pictóricos de Contrebia Belaisca (Botorrita, Zaragoza), pertenecen a la denominada casa Agrícola, una domus republicana de influjo helenístico sobre la cual M. Beltrán señaló la posibilidad de la existencia de pinturas de este estilo en las estancias 3-6 y 9-14. No obstante, conocemos únicamente los restos pertenecientes al cubículo 4, conformados por un zócalo pintado en negro y una zona 
media roja, así como una pilastra estucada en color blanco que compartimenta el espacio decorativo (Guiral y Mostalac 1987: 235; 1993: 368-370; 2011: 601). Junto a estos, encontramos también restos de sillares almohadillados y una cornisa de dentículos, la mayoría con monocromía roja o negra a excepción de un fragmento de imitación marmórea a base de vetas rojas sobre fondo ocre. En el caso de este último, contamos con una decoración similar en Cartagena (Fernández Díaz 1999: 370), perteneciente a un conjunto que describiremos más adelante, y entre los fragmentos objeto de este estudio.

El conjunto proveniente de Valdeherrera consta de un techo casetonado hallado sobre el pavimento del $\mathrm{cu}$ biculum 3.16 de la insula 3 , consistente en una retícula de casetones cuadrangulares $(3 \times 3)$ con anchas bandas de separación en las que se dispone una ranura pintada en rojo que presenta en su interior cuatro hojas de acanto y un botón polilobulado (Guiral e Íñiguez 2015: 102-104). Estos datos, junto con el propio contexto de la vivienda, permiten fecharlo en la segunda mitad del siglo II a.C., siendo un techo que guarda similitudes con el procedente de la Acrópolis de Populonia o el de la villa de San Vito en Salapia (Donati y Cavari 2007: 230-233), lo que lo convirtió en un ejemplar único en la Península hasta la aparición del conjunto de la c/ $\mathrm{Pa}$ las de Cartagena, que aunque en estado muy fragmentario, cuenta también con una estructura casetonada pero de cronología augustea y, en esta ocasión, con un posible casetón circular central del que partirán un número indeterminado de casetones hexagonales (en prensa).

De este grupo aragonés, el de Sekeiza/Segeda, con restos pictóricos provenientes de una estancia cuadrangular, hoy perdida, y clasificados como los más antiguos constatados en Hispania -mediados del siglo II a.C.-, parece ser el único correspondiente al estilo estructural griego, pues está formado por un plinto sobre el que se apoya el zócalo, compuesto por grandes ortostatos que probablemente darían paso a un despiece de sillares actualmente perdido (Guiral y Mostalac 2011: 598-601).

Para el caso de Carthago Nova, los restos de pintura mural pertenecientes al primer estilo pompeyano, proceden de las excavaciones realizadas entre 1989 y 1991 con el objetivo de delimitar el área arqueológica del anfiteatro romano y que, dadas las continuas remociones de tierra sufridas a lo largo de la historia, dificultan la lectura del contexto arqueológico. El conjunto, sin presencia de piqueteado en su capa superficial, debió pertenecer a un edificio datado a principios del siglo II a.C., pues los niveles de abandono de la segunda mitad de dicho siglo, probablemente relacionados con una profunda reforma de este como consecuencia de un cambio de tendencia o gustos del propietario así lo indican. Se trata de unos fragmentos que permiten reconstruir un alzado formado por una zona superior realizada a modo de un aparejo isódomo a base de hiladas de sillares almohadillados en estuco y pintados en varios colores (fig. 10.2), uno de ellos a imagen y semejanza de un mármol brecciato que presenta grandes similitudes con el conjunto del vestíbulo de la casa Samnita de Herculano (V, 1-2) o el del vestíbulo de la casa del Fauno (VI, 12) respectivamente (Borda 1958: 13-14 y 17). En este mismo conjunto se cuentan también diversos fragmentos de cornisas molduradas en estuco que, aunque podrían asociarse a otras estancias, tal vez formaran parte del friso que se situaría encima de esta zona de la citada pared y que presenta decoración denticulada propia del orden jónico (Fernández Díaz 1999; 2004: 502-503; 2011: 97-110) similar al caso que hemos citado más arriba correspondiente a los restos de la casa Agrícola de Contrebia Belaisca. No debemos olvidar, no obstante, el caso de la domus de los Delfines, del que únicamente puede señalarse la presencia de fragmentos pertenecientes a un bloque de aparejo isódomo en relieve de color rojo (Fernández Díaz 2004: 502-503; 2011: 112), así como una cronología similar a la de la plaza del Hospital, dado que la zona en que se ubica este edificio sufre un abandono generalizado a finales del siglo II a.C. y queda amortizado a finales del siglo I a.C. Si tenemos en cuenta que tanto en época tardorepublicana como altoimperial las domus más importantes de la ciudad se ubican topográficamente en la vertiente interior de las laderas que la circundan, podríamos pensar en la posible existencia de espacios destinados a alguna actividad artesanal como podría ser el caso de El Olivillo, aunque en esta ocasión distinta a la de producción de pescado.

Finalmente, del área catalana conservamos dos ejemplos para su comparación con el resto de la península: de las pinturas pertenecientes al ambiente $n^{\circ}$ 3 de la villa de Can Martí en Samalús (Vallès Oriental, Barcelona), únicamente existe la referencia a un conjunto formado por placas de colores amarillo y blanco en estuco sobre un fondo rojo, entendiendo estas placas como una imitación de sillares que sobresalen de la pared. Al margen de esta información, no contamos con mayores datos, ni tan siquiera gráficos, para un mejor análisis de este conjunto, situándose en torno a finales del siglo II a.C. a partir de las cronologías dadas para los mosaicos de esta estancia y las aledañas (Aquilué y Pardo 1990: 96-98). Asimismo, de las pinturas del 


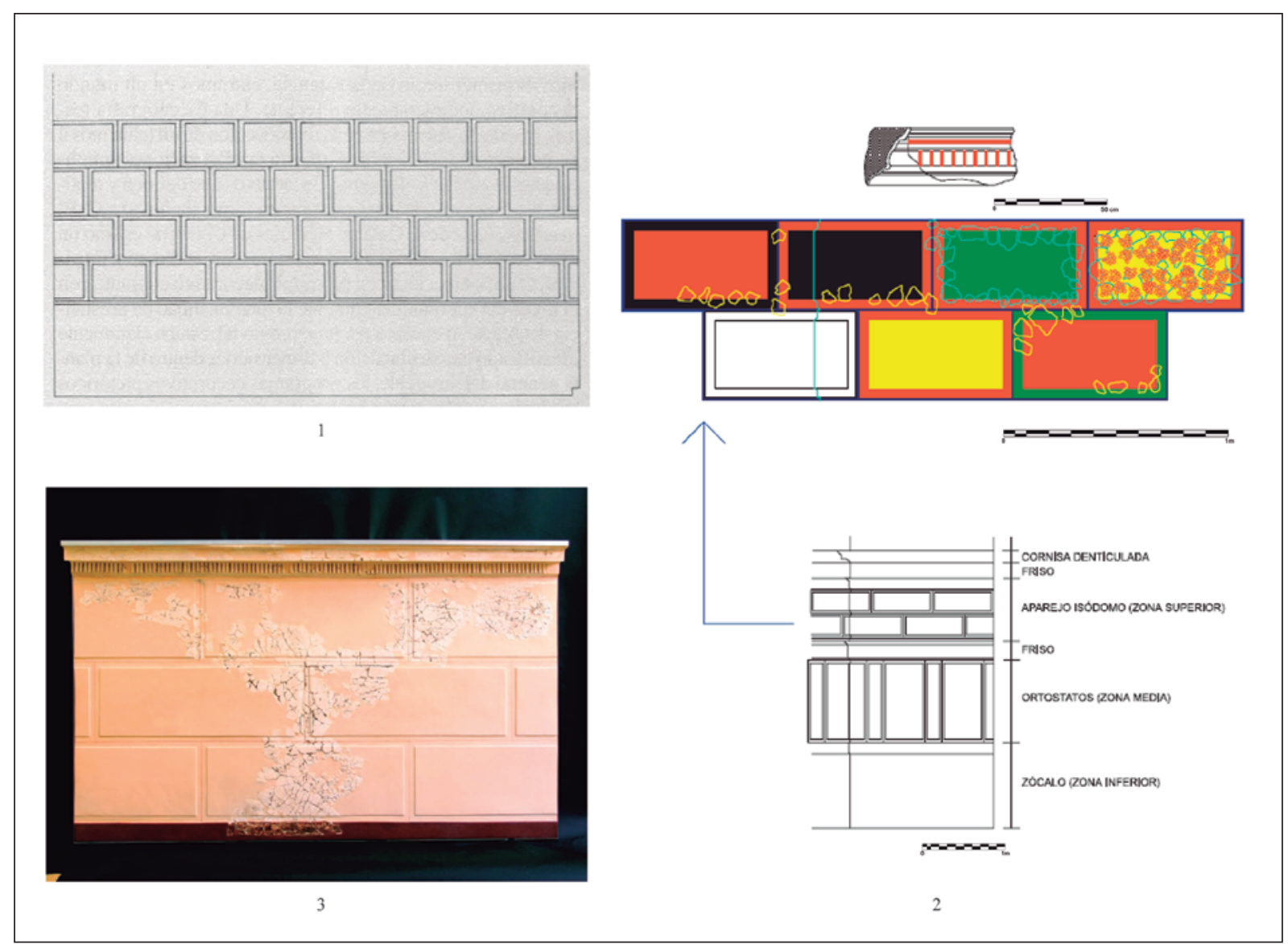

Figura 10. Ejemplos de I estilo en Hispania: 1. Azaila, 2. Carthago Nova, 3. Can Tacó.

castellum de Can Tacó-Turó d'en Roïna (MontmelóMontornès del Vallès, Barcelona) (fig. 10.3), contamos igualmente con escasa información, siendo los únicos datos que encontramos la aparición en el ambiente 5 de un derrumbe de pintura formado por sillares de imitación de mármol blanco y parte de una moldura denticulada, que la adscriben al primer estilo pompeyano y ofrecen la cronología propia de dicho estilo para ese espacio (Mercado et al. 2006: 253-254).

A la luz de estos datos, podemos advertir que la presencia del primer estilo pompeyano en España se ciñe a un escaso número de ejemplares, todos ellos ubicados dentro de la provincia Tarraconensis y muy especialmente en el área aragonesa. Este dato no sorprende si tenemos en cuenta las cronologías de la conquista de las distintas zonas de Hispania por Roma, lo que nos lleva a plantear que la ausencia de más testimonios respecto al primer estilo pompeyano en el resto del país se deba principalmente a la ausencia de intervenciones arqueológicas que hayan permitido sacarlos a la luz aún, o a la continua remodelación urbana que sufren aquellas ciudades que han mantenido su ocupación a lo largo del tiempo, impidiendo que aquellas estructuras más antiguas permanezcan intactas en la actualidad.

\section{OTROS RESTOS PICTÓRICOS DE INTERÉS}

Al margen de los datos de la UE 7016 referentes al primer estilo pompeyano, quisiéramos señalar aquí brevemente una serie de fragmentos pertenecientes al mismo sondeo, pero a la UE 7028, de cronología posterior puesto que contiene las primeras evidencias de terra sigillata itálica. Esta, ubicada por debajo de las UUEE 7005 y 7009, presenta un nivel de vertido caracterizado por la heterogeneidad de sus materiales arqueológicos, que responden a un origen triple: haliéutico - tal y como demuestran los numerosos fragmentos de ánforas salsarias de producción regional-, de consumo doméstico -a tenor de la abundante presencia de fauna terrestre y, en 
menor medida, de cerámica común a torno-y de carácter constructivo - llámese la atención acerca de los 58 fragmentos de estuco y pintura mural documentados así como de la aparición de nódulos de argamasa y tégulas quemadas, entre otros-.

Entre los fragmentos de pintura recuperados, encontramos dos en los que se aprecia un campo blanco con la representación de una pequeña fuente en color azul parcialmente conservada, sobre la que se apoya, un pajarillo de cuerpo negro y patas rojas. Si bien no se ha conservado la cabeza del mismo, este parece encontrarse inclinado hacia la fuente en un intento de beber de esta. A la derecha de la representación queda un trazo curvo en azul y sobre este dos arcos rojos tangentes y de diferente tamaño (fig. 11).

Estos fragmentos presentan una superficie pictórica estriada que ha sufrido abrasiones y conserva una ligera capa de cal blanca sobre los citados elementos que podría estar indicando un repinte posterior, al igual que en los fragmentos ya descritos de la UE 7016. En lo que respecta al mortero, se diferencian cuatro capas distintas, siendo la primera una fina capa de $0,05 \mathrm{~cm}$ correspondiente a la capa pictórica; una segunda de $0,7 \mathrm{~cm}$ formada casi en su mayoría por cal con presencia de arena fina; y las dos últimas, la primera de $1,4 \mathrm{~cm}$ y la segunda de hasta $2,6 \mathrm{~cm}$, de color marronácea y compuesta de arena fina tamizada y piedras de pequeño tamaño, siendo su estructura poco compacta. La capa termina con un reverso en espiga para su sujeción en la pared.

La escena representada es más propia de las imitaciones de jardines que encontramos a partir del tercer estilo pompeyano en la zona inferior o incluso en la zona media, en las que la presencia de aves como palomas, garzas, patos, ruiseñores o cornejas, constituyen un elemento bastante usual. Tal es el caso de las pinturas que encontramos en la Villa de Livia en Prima Porta a las afueras de Roma o en la casa del Bracciale d'Oro (VI 17, 42) y la casa della Venere in Conchiglia (II 3, 3) de Pompeya. No obstante, la calidad técnica que observamos en estos fragmentos no alcanza la de las composiciones itálicas de dicha época, mostrando un estilo y trazo más esquemático, probablemente por tratarse del trabajo de un aprendiz de un taller itálico, dado que en esta época aún no existirían talleres locales. Del mismo modo, el hallazgo de estos fragmentos en un nivel fechado en época tardorrepublicana hace difícil que podamos adscribirlos al tercer estilo pompeyano, por lo que es más probable que pertenezca a una composición del primer o segundo estilo diferente a la que conforman el resto de fragmentos que hemos analizado.
Los ejemplos de este tipo de decoración para las citadas fechas son escasos dada la ausencia, por norma general, de elementos figurados dentro del primer estilo fuera de la Península Itálica (De Vos 1977: 29-48) a diferencia del primer estilo estructural presente en el friso de la casa de los Comediantes de Delos (Bruneau et al. 1970) y a excepción de algunos ejemplos en el primer estilo propiamente pompeyano como el fauno danzante en la casa de Epidius Sabinus (IX 1, 22), los centauros de la exedra de Alejandro, roleos figurados y cortinaje de las estancias 44 y 31 respectivamente de la de la casa del Fauno (VI 12, 2) (Barbet 1985: figs. 14-15), en la casa VI 14, 40 (Laidlaw 1993: 231-232; Baldasarre et al. 2006: 77) o un pájaro pintado sobre un sillar de fondo amarillo del siglo III a.C. de la casa del Naviglio de Pompeya (VI 10, 11) (Pesando 2007: 3B.85, 321); únicamente contamos con un ejemplo con delfines en color verde y amarillo sobre un bloque de aparejo de color blanco proveniente de Fort Royal (Île SainteMarquerite, Francia) (Barbet 2008: figs. 20-22). Las muestras de estos elementos figurados son más numerosas en el segundo estilo, aunque igualmente escasas en contraposición a su presencia en los siguientes estilos, encontrándolas especialmente dentro de composiciones de arquitecturas ficticias de las zonas medias como es el caso de la representación de pavos reales sobre arquitectura ficticia de la habitación 15 de la villa de Poppea en Oplontis, decorando los frisos de estas en las zonas superiores como observamos en el oecus triclinar de la casa del Criptopórtico (I 6, 2-16) de Pompeya, o en la zona media de la pared, sobre guirnaldas que penden de los fustes de columnas pintadas en el $\mathrm{Cu}$ biculum 14 de la casa des Épigrammes (V 1, 18) (Barbet 1985: fig. 35).

\section{INTERPRETACIÓN DE LOS RESULTADOS Y CONCLUSIONES}

Hasta la fecha, a pesar de la convicción de la existencia del primer estilo pompeyano en la Bética, dada la larga historia de algunos de los enclaves de la provincia, los ejemplares pictóricos más antiguos identificados en dicha provincia no se remontaban más allá de época augustea con los provenientes de la zona de La Caleta dentro de la propia ciudad de Gades (Fernández Díaz 2010: 213) o los pertenecientes a las tumbas de la necrópolis de Carmo en Sevilla, datados en época julioclaudia (Abad y Bendala 1975: 323-324). No obstante, la ciudad es bien conocida desde antiguo, tal y como se puede atestiguar a partir de diversas fuentes escritas y 


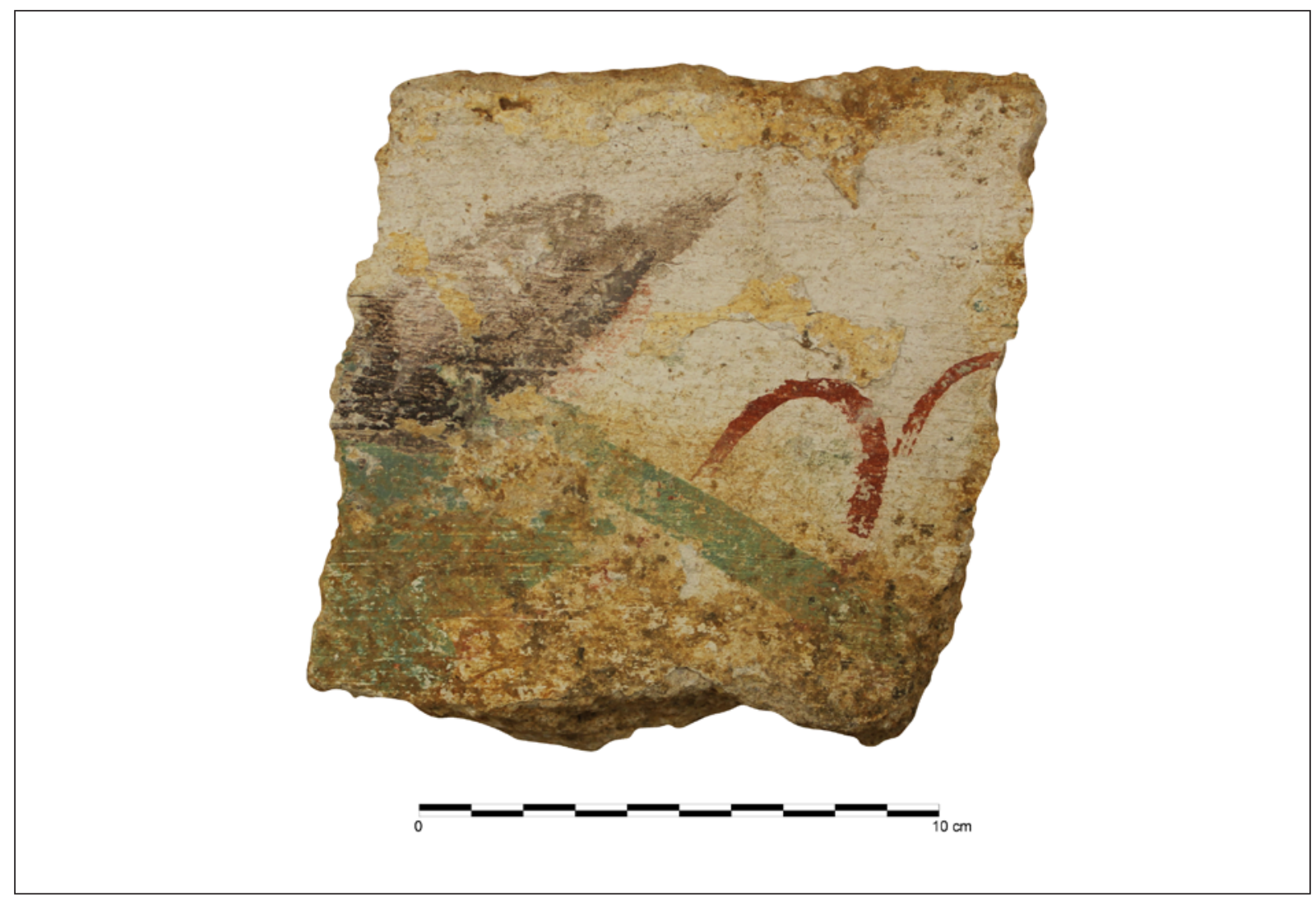

Figura 11. Fragmento de pintura mural con representación de un pequeño pájaro de patas rojas y cuerpo negro del que falta la cabeza y se encuentra apoyado en una fuente.

de los abundantes restos arqueológicos de la Gadir fenicia hallados bajo la misma, entre los cuales podemos citar los procedentes del teatro cómico, que dan buena muestra de la entidad de la ciudad en cronologías bien tempranas (Gener et al. 2015).

Gracias a la situación geográfica de esta ciudad, como nexo de unión entre el Mediterráneo y el Atlántico, su puerto debió suponer un enclave de gran interés para la conquista de Hispania, por lo que no es de extrañar que existiera una gran presencia de elementos de época republicana en la ciudad. Junto a esto, debemos tener en cuenta que la ciudad no es abandonada en ningún momento desde su ocupación, por lo que las distintas remociones de tierra y reurbanizaciones en diversas épocas han propiciado la pérdida de los vestigios más antiguos, algo que también sucede en otras ciudades como es el caso de Carthago Nova, donde los restos del primer estilo pompeyano también son escasos, tal y como hemos podido comprobar.

Si bien los restos pictóricos hallados en los sondeos descritos, y más concretamente, en las UUEE 2018,
2019, 3014, 3015, 3029 y 4027 que los componen, se encuadran en su mayoría en la transición del segundo al tercer estilo pompeyano o en este mismo, dato que encaja con la cronología -siglo I a.C. y primera mitad del siglo I d.C.- propuesta para estos estratos a partir del material cerámico -cerámica de barniz negro, terra sigillata itálica, cerámica de barniz rojo pompeyano y ánforas itálicas-, solo hemos analizado en profundidad parte de los restos pictóricos procedentes del sondeo 7 , dado que son los que se corresponden con el primer estilo pompeyano, además de hacer mención también a una serie de fragmentos que, aunque corresponden a otro conjunto y a otra unidad estratigráfica, provienen de ese mismo sondeo.

Si observamos los ejemplos pompeyanos que cuentan con la decoración del primer estilo, a pesar de la identificación de algún patrón en la distribución de colores (Laidlaw 1985: 25-31), como la inexistencia de dos bloques contiguos del mismo color a no ser que estuvieran dispuestos en una diagonal (Bruno 1969: 311), esta parece dejarse al azar en la mayoría de ellos. De 


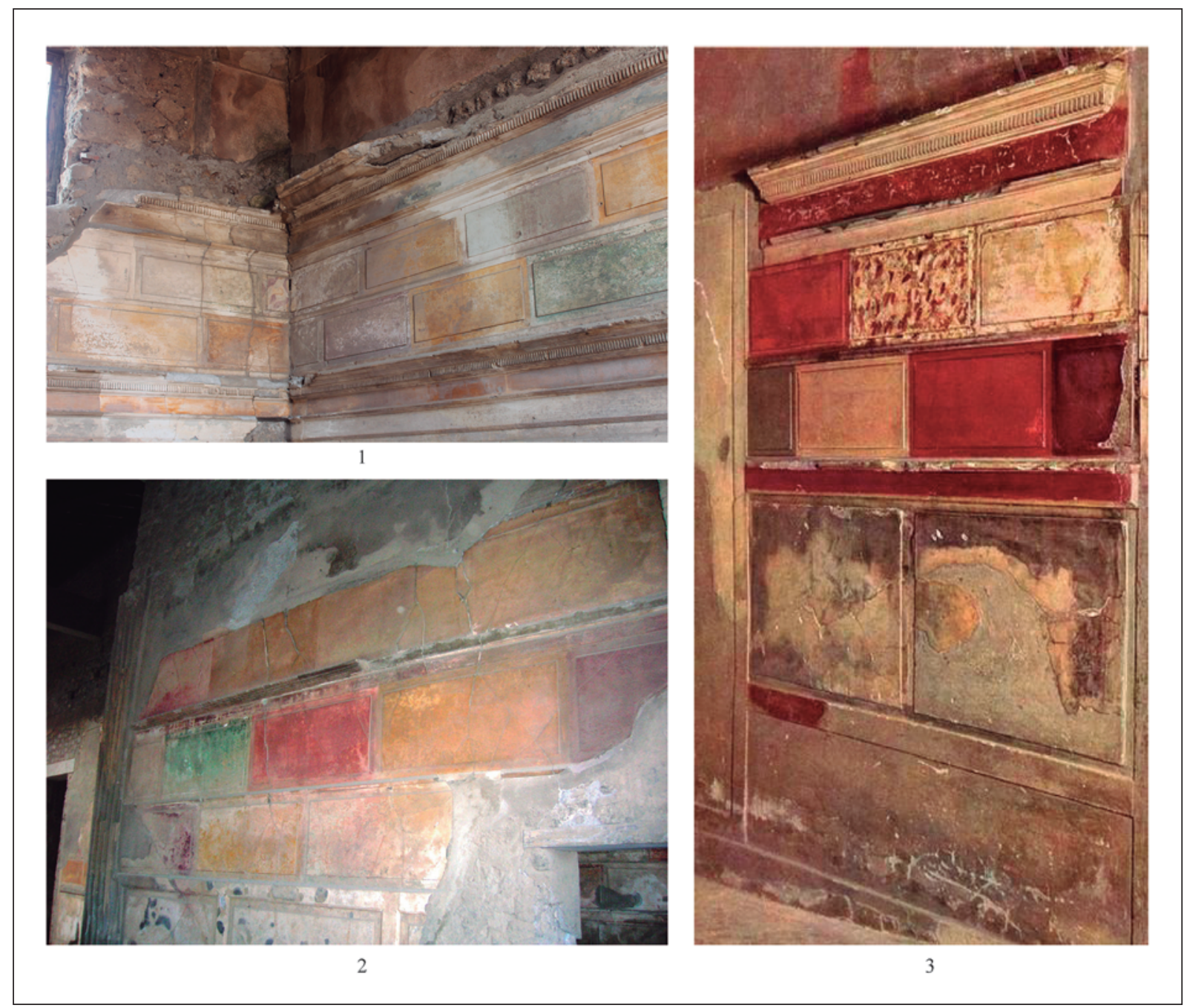

Figura 12. Ejemplos del I estilo pompeyano en Campania: 1. Casa de Sallustio en Pompeya (VI 2, 4), 2. Casa del Centauro en Pompeya (VI 9, 3/5), 3. Casa Samnita de Herculano (V, 1-2).

igual modo, la cantidad y variedad de imitación pétrea parece exceder de lo disponible en esos momentos en el territorio, al menos para los alzados, pudiendo inspirarse en los interiores enlucidos de otros lugares como Delos, Cosa y Morgantina (Bruno 1969: 305, 308-309), consiguiendo una variación local en Campania (Leach 2004: 63). En este sentido, si bien en el caso de El Olivillo, dos de los conjuntos parecen corresponder a una imitación de marmor numidicum, sin descartar la posibilidad de una representación de las vetas de madera como sucede en los ejemplos posteriores del segundo estilo pompeyano del cubiculum pintado de la domus 2 de Bilbilis (Calatayud) (Martín et al. 2007: 260) o en la habitación "D" de la casa de las dos Alcobas de Glanum en Francia (Barbet 1990: 110), en general se deja ver que no hay mucha preocupación por parte de los artesanos en representar los detalles precisos. Esta dejadez, debida a la falta de interés y/o disponibilidad de dichos materiales cuyo uso no se hace efectivo en los alzados arquitectónicos o en la escultura hasta fechas posteriores al primer estilo, hace que tal vez no se conozcan sus características o propiedades. Aquí, podemos observar esa dualidad, ya que se da una representación mayoritaria de piedra coloreada, al tiempo que una cierta dejadez en la representación de las características particulares de los materiales que se imitan.

La escasa variedad de piedra representada en El Olivillo que se desprende, no de su realidad sino más bien de su hallazgo en un vertedero, sigue la tónica general del primer estilo pompeyano, que se 
limita casi exclusivamente a dos tipos: el alabastro y la brecha, representados en muchos casos con gran libertad e inventiva haciéndose difícil su adscripción. Si bien, la imitación de un bloque en color monócromo uniforme es complicada de adscribir, cuando se trata de bloques con diversidad de formas y color, facilita la definición de una variedad específica de piedra, como el caso de los dos bloques de fondo amarillo con vetas sinuosas de color rojo. Aunque es difícil encontrar paralelos en la disposición, combinación y uso del color, contamos con algunos ejemplos pompeyanos donde se representan formas y colores de ortostatos o de bloques de aparejo isódomo ligeramente parecidos. Por ejemplo, dibujos ovoides irregulares de color amarillo, rojo, verde y blanco en una pequeña habitación al norte de la entrada a la casa dei Quattro Stili (I 8, 17/11), la habitación "g” que se abre en la esquina sureste del atrio de la casa del Cenacolo (V 2.h) (DAIR 40.314), el atrium, alae y tablinum de la casa de Sallustio (VI 2, 4) (fig. 12.1) (Laidlaw 1993: ills. 40-42, 330-331), la casa del Fauno (VI 12, 2), el cubiculum 3 de la casa del Centauro (VI 9, 3/5) (fig. 12.2) (Laidlaw 1985), el peristilo de la casa IX 3, 2 o el oecus "b" de la casa IX 1, 22 en Pompeya, o el vestíbulo de la casa Samnita de Herculano (V, 1-2) (fig. 12.3) en las que, entre otros (Laidlaw 1993: ill. 119, 346; Baldasare et al. 2006: 72-73), también aparecen bloques de color blanco y rojo de diferentes tamaños, así como de imitación de mármol veteado con formas ovaladas, en este caso más similar al ejemplo de Carthago Nova que al de Gades.

En la arquitectura doméstica y durante el período en que se produjo el primer estilo pompeyano, la evidencia de piedra y/o piedra marmórea se limita exclusivamente a los pavimentos, y especialmente de pequeño tamaño y número reducido, sobre todo, calizas locales de color uniforme y algún mármol importado, por tanto estas estaban asociadas a unos pavimentos simples de opera signina embellecidos con algunas teselas o fragmentos de mármol -opus scutulatum-(Gros 2010: 23$30)$, con excepciones más elaboradas como en la casa del Fauno (VI 12, 2-5), y en ellas, los artesanos se limitaban a intentar imitarlos. Si tenemos en cuenta esto, es probable que el o los suelos de la/s estancia/s a los que corresponden nuestras pinturas estuvieran decorados con pavimentos de opus signinum sin decoración o con algunas teselas, máxime si tenemos en cuenta que en la UE 7004 de este mismo sondeo y con semejante cronología, hay un fragmento que lo demuestra (fig. 13). Esta adscripción haría pensar en la posibilidad de que esa gran cantidad de fragmentos de color rojo con mortero compuesto por cerámica machacada y conglomerado de arena de playa y conchas, ya descritas, correspondieran no al suelo, sino más bien a parte del alzado de la pared, tal vez en relación con el aparejo isódomo anterior, o no, pero actuando de cocciopesto rojo para la zona inferior o zócalo, por lo que el resto de fragmentos descritos se situarían en la zona media y superior como incluimos en las restitución hipotética propuesta (fig. 14). Esta, a pesar de constatarse la presencia de aparejos isódomos con relieve real, imitaciones marmóreas, monocromías y cornisas estucadas con diferentes secuencias de molduras, no garantiza sin embargo una restitución ideal de "tipo itálico" debido al número insuficiente de fragmentos y al contexto del que provienen, pero hemos optado por incluirla para que sirva como base de partida en futuras investigaciones.

El cocciopesto u opus signinum de las fuentes, ha sido ampliamente tratado por la historiografía como pavimento, sin embargo, no así tanto como revestimiento de paredes, usado igualmente por los antiguos para proteger los muros de la humedad. Estaba constituido por una mezcla compacta de fragmentos de materiales cerámicos, generalmente reutilizados de tégulas y de ánforas, unidos con cal grasa que, cuando secaba, no dejaba penetrar el agua; una mezcla cuyo grosor podía oscilar entre 5 y $15 \mathrm{~cm}$. En la Antigüedad se usaba para revestir las cisternas, las bañeras, las terrazas exteriores, los impluvia y los zócalos de las paredes de las casas, o las estancias calientes. Ejemplos de ello los podemos observar en una de las paredes de la Fullonica (VI 14, 22), en una jamba situada en el callejón de las Termas (VII 6) y en una pared de la cocina "K" de la casa IX 1, 12 de Pompeya. Estos no serían extraños en las provincias, como podemos comprobar en un fragmento extraído del basurero de Blanes de Mérida que aún se encuentra en fase de estudio.

Además de la importancia que reviste la presencia de un primer estilo en dicha ciudad, hemos de destacar también los resultados que han proporcionado los análisis físico-químicos que se han llevado a cabo tanto en los pigmentos como sobre los morteros.

En relación con los pigmentos, la utilización de hematites para conseguir el color rojo en las decoraciones pictóricas es el más comúnmente usado entre los diversos conjuntos que encontramos a nivel peninsular, siendo mezclado junto con otros elementos como la calcita, también presente en nuestra muestra, para obtener distintas tonalidades más claras u oscuras (Edwards et al. 2003; Mateos y Ruiz 2015; Mateos et al. 2016), no detectándose aquí la presencia de otros minerales 


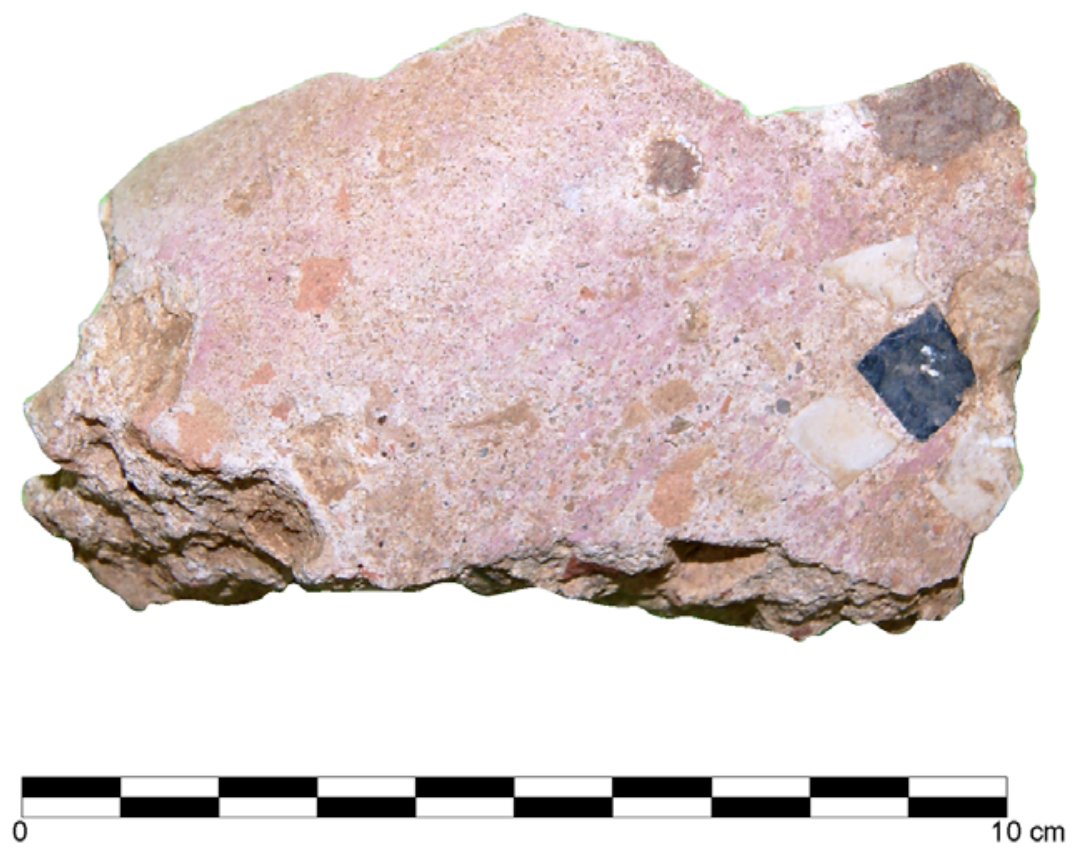

Figura 13. Fragmento de opus signinum teselado proveniente del sondeo 7.

como el cinabrio, mucho más preciado y que solo se encuentra en algunos conjuntos de mayor calidad, como podría ser el del establecimiento romano republicano de Can Tacó-Turó d'en Roïna (Montmeló-Montornès del Vallès, Barcelona) (Pitarch et al. 2010). En el caso de la goethita, este parece ser el mineral empleado durante época romana para crear una gran variedad de tonalidades amarillas (Edwards et al. 2009; Mateos y Ruiz 2015; Mateos et al. 2016), que también encontramos en otros yacimientos peninsulares, en algunos casos mezclados con calcita (Villar y Edwards 2005). Para el caso de Cádiz contamos también con los análisis realizados a un conjunto de pinturas extraído en la intervención de un solar en la calle Santa María 17-19 (Domínguez-Bella et al. 2003), algunas muestras de las cuales podrían pertenecer al tercer estilo pompeyano, lo que confirma una continuidad en el uso de los minerales para algunos de los pigmentos, como por ejemplo el amarillo mediante el uso de goethita o el rojo mediante el uso de hematites o cinabrio, así como otros elementos minoritarios en la composición como es la calcita y el cuarzo.
Por otra parte, debemos señalar también la aparición en los molinos de las cetariae excavadas en la calle San Nicolás de Algeciras en Cádiz (Bernal Casasola y Domínguez Bella 2011-2012), de restos de cinabrio machacado que nos indican la existencia de una actividad de fabricación de pigmentos y su empleo como colorante dentro de las industrias pesquero-conserveras. Teniendo en cuenta este dato, no es de extrañar que la cantidad de fragmentos pictóricos identificados en la zona de El Olivillo se encontrara en relación con restos de industrias de esta índole, máxime si aquí también hay pigmentos rojos y hematites procedentes de dos vertidos inmensos de murícidos machacados relacionados con los concheros para la producción de púrpura (Bernal et al. 2017b).

La existencia de polvo de mármol como material para la ejecución de la última capa de mortero que recibe la decoración pictórica, no se constata de forma generalizada en los conjuntos hispanos, a excepción de algunos provenientes de Bilbilis, tanto de contexto doméstico como público (Guiral y Martín-Bueno 1996: 505; Íñiguez Berrozpe 2014). La diferencia es que, en 


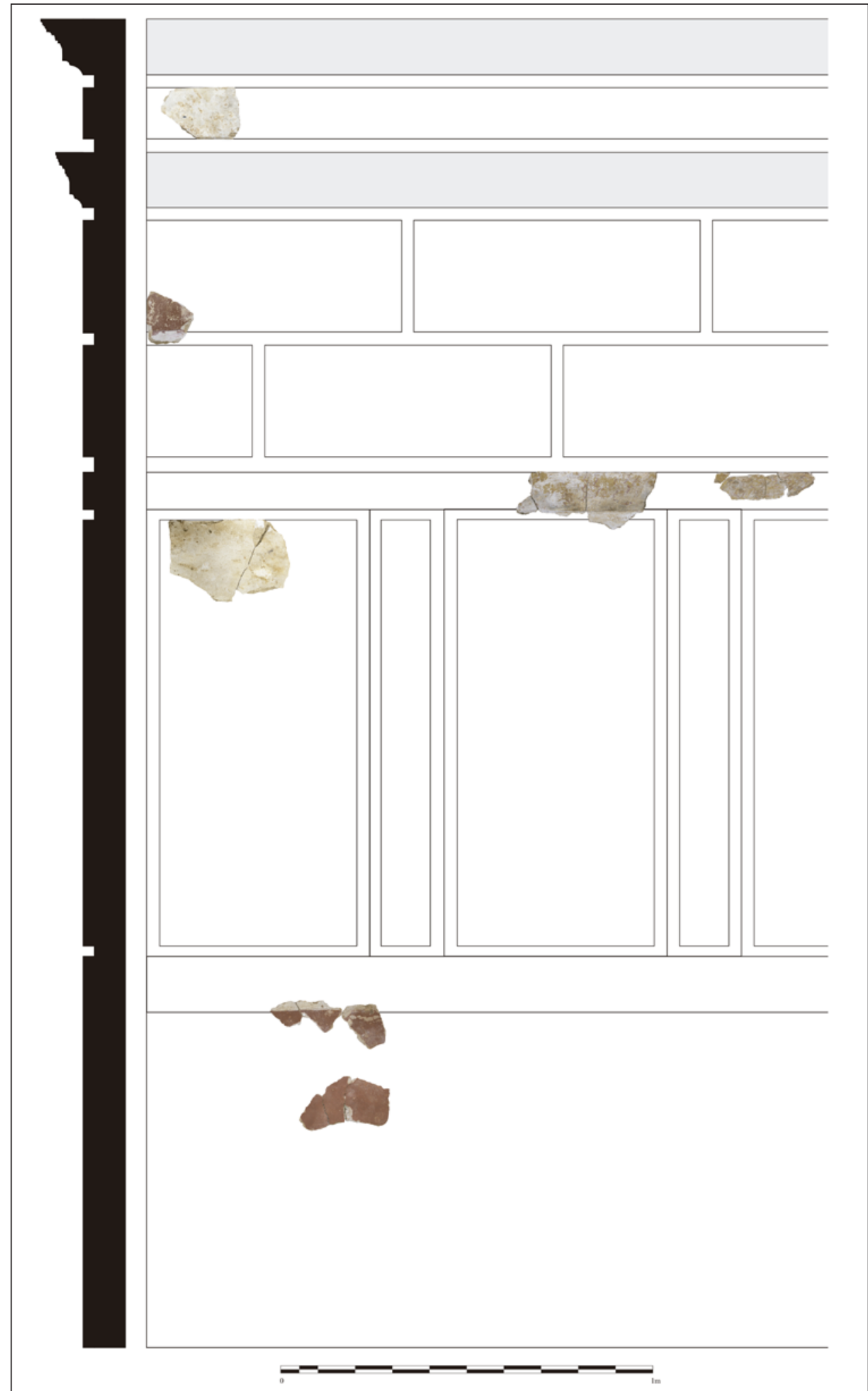

Figura 14. Restitución hipotética del posible alzado pintado que se derivaría del estudio de estas piezas del vertedero (Digitalización: L. Suárez Escribano). 
estos, el polvo de mármol es "esparita" o cristales de calcita, mientras que el de Cádiz es dolomita. Su presencia en los conjuntos del primer estilo pompeyano de esta última ciudad, vendría refrendado por la ausencia o la aparición en una concentración mucho menor de este elemento en el resto de fragmentos analizados, así como por la presencia cerca de Cádiz de uno de los pocos yacimientos de dolomita que existen en la Península, que explicaría la utilización de este mineral como elemento constructivo y la explotación de esta zona desde época antigua. Asimismo, debemos recordar que este mineral fue descrito por primera vez a partir de su análisis en edificios de la antigua Roma por el francés D. Dolomieu (1791), confirmando la información que aportan las fuentes respecto al empleo del polvo de mármol. En lo que a este estudio respecta, debemos señalar que en Cádiz ya contamos con restos pertenecientes al tercer estilo pompeyano procedentes del yacimiento de $\mathrm{La}$ Caleta que muestran en su mortero restos de polvo de mármol, lo que estaría indicando la pervivencia del empleo de este mineral para la ejecución de conjuntos pictóricos desde finales del siglo II-inicios del siglo I a.C. hasta al menos época augustea (Fernández Díaz 2010: 210). En este sentido, la utilización de polvo de mármol tal vez podría corresponder a una “innovación tecnológica" que, ampliamente conocida en Roma, fuese traída por los Cornelios Balbos, una ilustre familia muy relacionada con la urbs (Rodríguez Neila 2006 y 2011; Pina Polo 2011), concretamente Lucio Cornelio Balbo el Mayor en época de César, cronología más próxima al conjunto del primer estilo, y su sobrino, el Menor, en época de Augusto, como encargado de la construcción de la Neapolis, nueva ciudad de Cádiz, que podría corresponder a los conjuntos del tercer estilo de La Caleta y de la calle Santa María. Igualmente, debido a su hallazgo en conjuntos fechados tanto en el siglo I a.C. como en el I d.C., debemos relacionarlo, además, con las características de los materiales del entorno a las que los artesanos tenían acceso, pues sería complicado ver en este aspecto únicamente, la presencia y práctica de un taller concreto.

En lo que respecta a las capas de mortero, la cantidad de estas que encontramos dista bastante del número establecido por Vitruvio (VII 3), pero se acerca más a los datos aportados por Plinio, quien señala no más de cinco capas; o lo referido por Paladio, quien indica la existencia de entre dos y tres capas. Estos datos demuestran no solo que se produce una disminución en las capas desde el siglo II a.C. hasta el siglo IV d.C., sino que en las provincias esta cantidad se reduce antes probablemente debido a que la distancia con respecto a los modelos itálicos da lugar a una alteración de la técnica. En el caso de los análisis de las pinturas de la calle Santa María 17-19, encontramos una composición muy similar en los morteros a lo visto en El Olivillo, estando formados esencialmente por calcita y cuarzo, así como arena de playa y restos de conchas, además de diferenciar la presencia de granos de mármol de hasta $1 \mathrm{~mm}$ de diámetro (Domínguez-Bella et al. 2003) que confirman la continuidad de la técnica empleada en la ejecución de los morteros desde época republicana hasta el Alto Imperio.

A este respecto podemos señalar también que, si bien el sistema de sujeción en cañizo presente en la mayoría de fragmentos analizados suele asociarse a techos, el estudio estilístico indica la pertenencia de estos fragmentos a una zona media-alta de la pared, un sistema de sujeción no muy común para estas zonas, en las que suele utilizarse el reverso en espiga. Este dato podría estar indicando una cronología más antigua o el trabajo de un taller concreto con una técnica distinta. No obstante, la utilización de cañizo, quizá como refuerzo del mortero que une a un muro de arcilla, técnica que también recomienda Vitruvio (VII 3, 11), se localiza en algunos ejemplos posteriores como en la casa de la Cisterna de Bilbilis de época flavia (Guiral Pelegrín y Martín Bueno 1996). Junto a esto, la presencia de cerámicas de gran tamaño a la que hacíamos referencia más arriba podría indicarnos su pertenencia, aunque no de forma inequívoca, a la decoración de un complejo termal o relacionado con el agua, dado que esta es empleada como absorción de la humedad y suele ir destinada a la zona de los zócalos, algo que no ocurre aquí.

A la luz de estos nuevos datos, creemos que este estudio supone un importante avance en el conocimiento, no solo del primer estilo pompeyano a nivel peninsular, sino también en relación al estudio técnico respecto a la elaboración de morteros y pigmentos en época republicana. En este sentido, pese a la clara llegada de estos modelos de la mano de artesanos itálicos, así como probablemente de las novedades técnicas fruto de una estrecha relación entre la ciudad y la urbs, vemos también una adaptación de estas a las posibilidades que la propia $G a$ des ofrece y que sin duda debió darse en la práctica totalidad de las ciudades del Imperio en lo que respecta a la captación de recursos y su aplicación en la construcción.

\section{Agradecimientos}

Este trabajo ha sido realizado dentro del marco del proyecto de investigación Pictores et officinae per provincias. La circulación de modelos pictóricos urbanos y 
rurales por el Sur de la Tarraconense y de la Lusitania desde una perspectiva integral (HAR2016-7487-P) y del proyecto GARVM II (HAR2016-78691P) financiados por el Ministerio de Economía y Competitividad del Gobierno de España; así como del proyecto Arqueostra, del Programa Operativo Feder-Andalucía 2014-2020. Asimismo, agradecemos a la Fundación Oriol Urquijo la concesión de una beca predoctoral que resulta de gran ayuda para facilitar el trabajo de uno de los miembros de dicho Proyecto.

\section{BIBLIOGRAFÍA}

Abad Casal, L. y Bendala Galán, M. (1975): “La Tumba de Servilia de la necrópolis romana de Carmona: su decoración pictórica". Habis 6: 295-326.

Abascal Palazón, J. M. y Ramallo Asensio, S. F. (1997): La ciudad de Carthago Nova: la documentación epigráfica. Murcia, Universidad de Murcia.

Acero Pérez, J. (2015): La gestión de los residuos en Augusta Emerita (Mérida, España). Siglos I a.C.VII d.C. Mérida, Universidad de Extremadura.

Alabe, F. (1994): La peinture des maisons a Delos. Banalite decorative hellenistique. Lille, ANRT.

Aquilué, X. y Pardo, J. (1990): "La villa romana de Can Martí (Samalús, Vallès Oriental)". Cypsela VIII: 87-100.

Baldasarre, I.; Pontrandolfo, A.; Rouveret, A. y Salvadori, M. (2006): Pittura romana, dell'ellenismo al tardo-antico. Milán, Federico Motta Editore.

Barbet, A. (1985): La peinture murale romane. París, Picard.

Barbet, A. (1987): "La diffusion des I, II et III styles pompéiens en Gaule", en Pictores per provincias. Actes du III Colloque International su la Peinture Murale Antique: 7-27. Avenches (1986), Avenches, Université de Lausanne.

Barbet, A. (1990): "Les peintures de Glanum: une relecture”. Gallia 47: 103-134. DOI: https://doi. org/10.3406/galia.1990.2905

Barbet, A. (2008): La peinture murale en Gaule Romaine. París, Picard.

Barbet, A. (2009): La peinture murale romaine. Les styles décoratifs pompéiens. Paris, Picard.

Becatti, G. (1961): Scavi di Osti. IV. Mosaici e pavimenti marmori. Roma, Libreria dello Stato.

Bernal-Casasola, D. y Domínguez Bella, S. (2011-2012): "Colorantes y pigmentos en las pesquerías hispanorromanas". CuPAUAM 37-38: 671-685. DOI: http:// dx.doi.org/10.15366/cupauam2012.38.037
Bernal-Casasola, D. y Lara, M. (2012): "Desenterrando a Gades. Hitos de la arqueología preventiva, mirando al futuro", en J. Beltrán Fortes y O. Rodríguez Gutiérrez (eds. cient.), Hispaniae Urbes. Investigaciones arqueológicas en ciudades históricas: 423-473. Sevilla, Universidad de Sevilla.

Bernal-Casasola, D. y Vargas, J.M. (2017): “El clíbano decorado de El Olivillo: un posible brasero de tradición helenística en Gades". Boletín de la Sociedad de Estudios de la Cerámica Antigua en Hispania 8: 36-41.

Bernal-Casasola, D. y Vargas Girón, J.M. (2019): “El Testaccio haliéutico de Gades", en D. Bernal-Casasola, J.M. Vargas Girón y M. Lara Medina eds., 7 metros de la Historia de Cádiz. Arqueología en El Olivillo y en el Colegio Mayor Universitario, Cádiz: 237-327.

Bernal-Casasola, D.; Vargas, J.M.; Gómez, M.S.; Lara, M. y Retamosa, J.A. (2017a): "El Testaccio de Gades. Un singular hallazgo de ámbito portuario en las excavaciones de El Olivillo", en IV Congreso Internacional de la SECAH - Ex oficina hispana. Opera fictiles. Estudios transversales sobre cerámicas antiguas de la Península Ibérica. Valencia (2017), en prensa.

Bernal-Casasola, D.; Vargas, J.M.; Cantillo, J.J.; Domínguez-Bella, S.; Lara, M. y Gómez-Muñoz, M.S. (2017b): "Purple Dye of the Cornelii Balbi. First results of the Shell middens and pigments from El Olivillo, Cádiz", en $5^{a}$ Reunião Cientifica de Arqueomalacología da Península Ibérica - encontro de Zooarqueologia Ibérica, Book of Abstracts, EZI 2017 - 5RCAPI: 37-38. Faro (2017), en prensa.

Beyen, H. G. (1938): Die pompejanische Wanddekoration vom zweiten bis zum vierten Stil I. La Haya, Springer Netherlands.

Blanco, F.J. (1991): "Excavaciones de urgencia en un solar de la Calle Gregorio Marañón. Cádiz”. Anuario Arqueológico de Andalucía III: 78-81.

Blanco, F.J. (1996): Informe arqueológico preliminar de un solar en c/ Venezuela, $n^{\circ} 3$. Ejemplar inédito depositado en la Delegación Provincial de Cultura de Cádiz.

Blanes, C. (1997): Informe intervención arqueológica de urgencia c/ Pericón de Cádiz, no 10, Cádiz. Ejemplar inédito depositado en la Delegación Provincial de Cultura de Cádiz.

Borda, M. (1958): La pittura romana. Milán, Editrice.

Boulard, M. (1908): Peintures Murales et Mosaiques de Delos. Monuments et mémories de la Fondation Eugène Piot 14. Paris, Académie des Inscriptions et Belles-Lettres. 
Brun, J. P. (2008): "Uno stile zero? Andron e decorazione pittorica anteriore al primo stile nell'insula I 5 di Pompei”, en P. G. Guzzo y M. P. Guidobaldi (eds.), Nuove ricerche archeologiche nell'area vesubiana (scavi 2003-2006): 61-70. Roma, L'Erma di Bretschneider.

Bruneau, Ph.; Vatin, C. y Bezerra de Meneses, U. (1970): "L'Îlot de la Maison des Comédiens". Exploration Archéologique de Dèlos 27: 151-193.

Bruno, V. J. (1969): "Antecedents of the Pompeian First Style”. AJA 73: 305-317. DOI: https://doi. org/10.2307/503512

Cabré, J. (1925): Los bronces de Azaila. Archivo Espa

ñol de Arte y Arqueología 3. Madrid, Centro de Estudios Históricos.

Cánovas Uberas, A. y Guiral Pelegrín, C. (2007): “Las musas de Gades (Cádiz, España)", en Circulación de temas y sistemas decorativos en la pintura mural antigua. Actas del IX Congreso Internacional de la Association Internationale pour la Peinture Murale Antique (AIPMA): 487-490. Zaragoza-Calatayud (2004), Zaragoza, Institución Fernando El Católico.

Clarke, J. R. (1991): The Houses of Roman Italy 100 B.C.-A.D. 250. Ritual, Space and Decoration. Berkeley, University of California Press.

De Vos, M. (1977): "Primo stile figurato e maturo quarto stile negli scarichi proveniente delle macerie del terremoto del 62 d.C. a Pompei". Mededelingen van het Nederlands Instituut te Rome XXXIX: 29-47.

Dolomieu, D. (1791): "Sur un genre de pierres calcaires très-peu efervescentes avec les acides \& phosphorescentes par la collision". Journal de Physique et d'Histoire naturelle XXXVIII: 3-48.

Domínguez-Bella, S.; Gener Basallote, J. M.; Kakoulli, I.; Jurado Fresnadillo, G. y Durante Macias, A. (2003): "Informe de la actuación "arqueometría del patrimonio histórico de Cádiz: las pinturas romanas de la Neápolis gaditana. Estudio de las pinturas murales y estucos de la C/Santa María No 17-19 (Cádiz)". Anuario Arqueológico de Andalucía Vol. 2: 119-129.

Donati, F. y Cavari, F. (2007): "Sistemi di I stile in Etruria: nuovi dati dallo scavo dell'acropoli di Populonia", en Circulación de temas y sistemas decorativos en la pintura mural antigua. Actas del IX Congreso Internacional de la Association Internationale pour la Peinture Mural Antique (AIPMA): 227-234. Zaragoza-Calatayud (2004), Zaragoza, Institución Fernando el Católico.

Dörpfeld, W. (1911): "Zu den Bauwerken Athens". Athen Milttelunger 36: 39-72. DOI: https://doi. org/10.11588/diglit.37288.7
Edwards, H. G. M.; Middleton, P. S. y Hargreaves, M. D. (2009): "Romano-British wall painting: Raman spectroscopic analysis of fragments from two urban sites of early military colonization". Spectrochimica Acta Par A: Molecular and Biomolecular Spectroscopy 73: 553-560. DOI: https://doi.org/10.1016/j. saa.2008.10.027.

Edwards, H. G. M.; Middleton, P. S.; Jorge Villar, S. E. y De Faria, D. L. A. (2003): "Romano-British wallpainting II: Raman spectroscopic analysis of two villa sites at Nether Heyford, Northants". Analytica 36: Chimica Acta 484: 211-221. DOI: https://doi. org/10.1016/S0003-2670(03)00333-7

Ehrhardt, W. (2012): Dekorations- und Wohnkontext. Beseitigung, Restaurierung und Konservierung von Wandbemalungen in den kampanischen Antikestätten. Wiesbaden, L. Reichert.

Expósito, J.A. (2007): Las factorías de salazón de Gades (ss. II a.C.-IV d.C.). Estudio arqueológico y estado de la cuestión. Trabajo de Investigación de Tercer Ciclo. Universidad de Cádiz. Inédito.

Fernández Díaz, A. (1999): "Pinturas murales del I estilo pompeyano en Cartagena". Archivo Espanol de Arqueología 72: 259-263. DOI: https://doi. org/10.3989/aespa.1999.v72.304

Fernández Díaz, A. (2004): "Decoración pictórica y en estuco de algunos elementos arquitectónicos de la ciudad romana de Carthago Nova", en La decoración arquitectónica en las ciudades romanas de occidente. Actas del Congreso Internacional: 501-517. Cartagena (2003), Murcia, Universidad de Murcia.

Fernández Díaz, A. (2008): La pintura mural romana de Carthago Nova. Evolución del programa pictórico a través de los estilos, talleres y otras técnicas decorativas. Murcia, Museo Arqueológico de Murcia.

Fernández Díaz, A. (2010): "Pintura", en P. León (ed.), Arte romano de la Bética. Mosaico. Pintura. Manufacturas (Vol.2): 191-274. Sevilla, Fundación Focus Abengoa.

Gener Basallote, J. M.; Navarro García, M. A.; Pajuelo Sáez, J. M.; Torres Ortiz, M. y López Rosendo, E. (2015): “Arquitectura y urbanismo de la Gadir fenicia: el yacimiento del "Teatro Cómico" de Cádiz", en M. Botto (ed.), Los fenicios en la bahía de Cádiz. Nuevas investigaciones: 14-50. Roma, Fabrizio Serra.

Gros, P. (2010): "Lithostroton, opus sectile et scutulatum d'après les textes et l'archéologie", en Pavimenti lapidei del Rinascimento a Venezia: 23-30. Venezia, Istituto veneto di scienze, lettere ed arti. 
Guillaud, J. y M. (1990): La peinture à fresque au temps de Pompéi. Paris, New York.

Guiral Pelegrín, C. e Íñiguez Berrozpe, L. (2015): “El techo casetonado de la Insula 3 de Valdeherrera", en J.C. Sáenz Preciado y M. A. Martín-Bueno (eds.), La ciudad celtíbero-romana de Valdeherrera (Calatayud, Zaragoza): 102-106. Zaragoza, Universidad de Zaragoza.

Guiral Pelegrín, C. y Martín-Bueno, M. (1996): Bilbilis I. Decoración pictórica y estucos ornamentales. Zaragoza, Institución Fernando el Católico.

Guiral Pelegrín, C. y Mostalac Carrillo, A. (1987): "Avance sobre la difusión de los cuatro estilos pompeyanos en Aragón (España)", en Pictores per provincias. Actes du III Colloque International su la Peinture Murale Antique. Cahier d'Archéologie Romande 43: 233-241. Avenches (1986), Avenches, Université de Lausanne.

Guiral Pelegrín, C. y Mostalac Carrillo, A. (1993): “Influencias itálicas en los programas decorativos de cubicula y triclinia de época republicana y altoimperial en España. Algunos ejemplos representativos". Espacio, Tiempo y Forma Serie I: 365-392. DOI: https://doi.org/10.5944/etfi.6.1993.4593

Guiral Pelegrín, C. y Mostalac Carrillo, A. (2011): "Programas decorativos de época republicana en el valle medio del Ebro: conservadurismo y progresismo", en C. Balmelle, H. Eristov y F. Montier (eds.), Décor et architecture en Gaule entre l'Antiquité et le haut Moyen Âge, mosaïque, peinture, stuc (Aquitania, Sup. 20): 597-609. Bordeaux.

Heras Mora, F. J.; Fernández Díaz, A. y Bustamante Álvarez, M. (2014): "Decoración parietal de $A u$ gusta Emerita, Repertorio pictórico y contexto arqueológico a partir de las excavaciones de un vertedero del suburbio norte", en N. Zimmermann (ed.), Antike malerei zwischen lokalstil und zeitstil. Akten des XI. Internationalen Kolloquiums der AIPMA: 461-471. Éfeso (2010), Viena, Verlag der Österreichischen Akademie der Wissenschaften.

Íñiguez Berrozpe, L. (2014): La pintura mural romana de ámbito doméstico en el Conventus Caesaraugustanus durante el siglo I d.C.: Talleres y Comitentes. Tesis Doctoral. Universidad de Zaragoza. Inédita.

Laidlaw, A. (1985): The first Style in Pompeii: painting and architecture. Archaeologica LVII. Roma, Giorgio Bretschneider.

Laidlaw, A. (1993): "Le Ier style", en La Peinture de Pompéi: 227-235. París, Éditions Hazan.

Lara Vives, G.; Mendiola Tébar, E. M. y López Seguí, E. (2009): "Un cuenco de cerámica helenística de relieves procedente de la Villa Romana Huerta del Paturro (Cartagena)". Mastia 8: 35-41.

Leach, E. W. (2004): The Social Life of Painting in Ancient Rome and the Bay of Naples. Cambridge, Cambridge University Press.

Martín Bueno, M.; Lope Martínez, J.; Sáenz Preciado, C. y Uribe, P. (2007): "La domus 2 del Barrio de las Termas de Bilbilis: la decoración del II estilo pompeyano", en B. Perrier (ed.), Villas, maisons, sanctuaires et tombeaux tardo-républicains: Découvertes et relectures récentes. Actes du Colloque Internacional de Saint-Romain-en-Gal en l'honneur d'Anna Gallina Zevi: 235-271. Vienne-Saint-Romain-en-Gal (2007), Roma, Quasar.

Mateos Luque, L. D.; Cosano, D.; Osuna, S. y Ruiz, J. R. (2016): "Nuevos análisis de pigmentos por espectroscopía Raman: villa romana de Priego de Córdoba y Cerro de las Cabezas de Fuente Tójar (Córdoba) y entorno". Antiqvitas 28: 109-118.

Mateos Luque, L. D. y Ruiz, J. R. (2015): “Análisis de pigmentos por espectroscopía Raman de la villa romana de El Ruedo (Almedinilla, Córdoba)". Antiqvitas 27: 69-83.

Mau, A. (1882): Geschichte der dekorativen Wandmalkerei in Pompeji. Berlín, Reimer.

McAlpine, L.J. (2014): Marble, memory and meaning in the four pompeian styles of Wall painting. Michigan, University of Michigan.

Mercado, M.; Palet, J. M.; Rodrigo, E. y Guitart, J. (2006): "El castellum de Can Tacó/turó d'en Roina (Montemló/Montornès) i la romanització de la Laietània Interior. Cap a un estudi arqueològic del jaciment i del territorio". Notes 21: 241-266.

Mols, S. T. A. M. (2005): "Il Primo Stile "retró": dai Propilei di Mnesicle a Pompei”, en S. T. A. M. Mols y E. M. Moorman (eds.), Omni pede stare. Saggi in Memoriam J. A. de Waele. Studi della Soprintendenza Archeologica di Pompei 9: 243-246. Nápoles, Electa Napoli and Ministero per i Beni e le Attività Culturali.

Morricone, M. L. (1971): Pavimenti di signino repubblicani di Roma e dintorni. Roma, Istituto Poligrafico dello Stato.

Mostalac Carrillo, A. y Guiral Pelegrín, C. (1992): "Decoraciones pictóricas y cornisas de estuco del Cabezo de Alcalá de Azaila (Teruel)". Revista d'Arqueologia de Ponent 2: 123-153.

Pajuelo, J.M. (2000): Informe de la intervención de urgencia en el solar $n^{\circ} 2$ y 4 de la calle Chile. Ejemplar inédito depositado en la Delegación Provincial de Cultura de Cádiz. 
Pajuelo, J.M. (2001): Seguimiento arqueológico del vaciado del solar 2, 4 y 4D de la calle Chile y $n^{\circ} 5$ de la calle San Rafael. Memoria depositada en la Delegación Provincial de Cultura de la Junta de Andalucía en Cádiz.

Perdigones, L. y Muñoz, A. (1987): “Excavaciones de urgencia en un solar de la calle Doctor Gregorio Marañón (Cádiz) en 1985”. Anuario Arqueológico de Andalucía III: 55-57.

Perdigones, L. y Muñoz, A. (1990): "Excavaciones de urgencia en un solar de la C/ Doctor Gregorio Marañón. Cádiz". Anuario Arqueológico de Andalucía III: 95-98.

Pesando, F. (2007): "I giardini nelle residenze di lusso romane: la documentazione dell'area vesubiana", en G. di Pasquale y F. Paolucci (eds.), Il giardino antico da Babilonia a Roma. Scienza, arte e natura: 118-127. Florencia, Sillabe.

Pina Polo, F. (2011): "Los Cornelio Balbos: clientes en Roma, patronos en Gades", en A. Sartori y A. Valvo (eds.), Identità e autonomía nel mondo romano occidentale. Iberia-Italia. Italia-Iberia. III Convegno Internazionale di Epigrafia e Storia Antica. Epigrafia e Antichità 29: 335-353. Faenza, Fratelli.

Pineda, P. (2012): A.A.P. Aparcamiento subterráneo de Santa Bárbara, Cádiz. Memoria final de actuación. Ejemplar inédito depositado en la Delegación Provincial de Cultura de Cádiz.

Pitarch, A.; Queralt Mitjans, I.; Álvarez Pérez, A. y Guitart Durán, J. (2010): “Caracterización de estucos y pigmentos del establecimiento romano republicano de Can Tacó-Turó d'en Roïna (MontmelóMontornès del Vallès, Barcelona)", en Actas del VIII Congreso Ibérico de Arqueometría: 329-336. Teruel (2009), Teruel, Seminario de Arqueología y Etnología Turolense.

Ramallo Asensio, S. F. y Ruiz Valderas, E. (2010): "Carthago de Hispania, emporio comercial del Mediterráneo occidental", en Simulacra Romae II: Rome, les capitales de province (capita provinciarum) et la création d'un espace commun européen: une approce archéologique: 95-110. Reims (2008), Reims, Société Archéologique Champenoise.

Remolà Vallverdú, J. A. y Acero Pérez, J. (2011): La gestión de los residuos urbanos en Hispania. Mérida, Consejo Superior de Investigaciones Científicas.

Rodríguez Neila, J. F. (2006). "Los Cornelios Balbo de Gades: las claves de su promoción social y política en Roma", en J. F. Rodríguez Neila y E. Melchor Gil (eds.), Poder central y autonomía municipal: la proyección pública de las élites romana de Occidente: 131-184. Córdoba, Universidad de Córdoba.

Rodríguez Neila, J. F. (2011): "Los Cornelios Balbos. Política y mecenazgo entre Gades y Roma”, en A. Arévalo González y D. Bernal-Casasola (coords.), El Theatrum Balbi de Gades: Actas del Seminario "El Teatro Romano de Gades. Una mirada al futuro”: 307-447. Cádiz, Universidad de Cádiz.

Seiler, F. (2011): "Questioni intorno un complesso di pitture ellenistiche singolari a Pompei”, en G. Franceso La Torre y M. Torelli (eds.), Pittura Ellenisitca in Italia e in Sicilia. Linguaggi e tradizioni: 499517. Roma, Giorgio Bretschneider.

Strocka, V. M. (1996): "Stili pompeiani”, Enciclopedia dell'Arte Antica 2 (Suppl. IV). Roma, Istituto della Enciclopedia Italiana.

Torelli, M. y Marcattili, F. (2010): "La decorazione parietale domestica romano-italica tra fase medio-repubblicana e cultura della luxuria", en XVII International AIAC Congress. Meetings between Cultures in the ancient Mediterranean: 40-56. Roma (2008), Roma, Bolletino di Archeologia online.

Villar, S. E. J. y Edwards, H. G. M. (2005): “An extensive color palette in Roman villas in Burgos, Northern Spain: a Raman spectroscopic analysis". Analytical and Bioanalytical Chemistry 382: 283289. https://doi.org/10.1007/s00216-004-2876-7

Vitruvio (1934): De Architectura. Granger F. (translator), Vol. II. Cambridge, Loeb Classical Library.

Wallace-Hadrill, A. (1994): Houses and Society in Pompeii and Herculaneum. Princeton, Princeton University Press. 